\title{
De novo venom gland transcriptomics of Calliophis bivirgata flaviceps: uncovering the complexity of toxins from the Malayan blue coral snake
}

\author{
Praneetha Palasuberniam ${ }^{1,2}$ (D), Kae Yi $\operatorname{Tan}^{3}$ (1), Choo Hock $\operatorname{Tan}^{1 *}$ (1) \\ ${ }^{1}$ Venom Research and Toxicology Laboratory, Department of Pharmacology, Faculty of Medicine, University of Malaya. Kuala Lumpur, Malaysia. \\ ${ }^{2}$ Department of Biomedical Sciences, University Malaysia Sabah, Faculty of Medicine and Health Sciences, Kota Kinabalu, Sabah, Malaysia. \\ ${ }^{3}$ Protein and Interactomics Laboratory, Department of Molecular Medicine, Faculty of Medicine, University of Malaya. Kuala Lumpur, Malaysia.
}

\section{Keywords:}

Three-finger toxins

Delta-elapitoxin-CB1a

Calliotoxin

Maticotoxin

Snakebite

Envenomation

\begin{abstract}
Background: The Malayan blue coral snake, Calliophis bivirgata flaviceps, is a medically important venomous snake in Southeast Asia. However, the complexity and diversity of its venom genes remain little explored.
\end{abstract}

Methods: To address this, we applied high-throughput next-generation sequencing to profile the venom gland cDNA libraries of $C$. bivirgata flaviceps. The transcriptome was de novo assembled, followed by gene annotation, multiple sequence alignment and analyses of the transcripts.

Results: A total of 74 non-redundant toxin-encoding genes from 16 protein families were identified, with 31 full-length toxin transcripts. Three-finger toxins (3FTx), primarily delta-neurotoxins and cardiotoxin-like/cytotoxin-like proteins, were the most diverse and abundantly expressed. The major 3FTx (Cb_FTX01 and Cb_FTX02) are highly similar to calliotoxin, a delta-neurotoxin previously reported in the venom of C. bivirgata. This study also revealed a conserved tyrosine residue at position 4 of the cardiotoxin-like/cytotoxin-like protein genes in the species. These variants, proposed as Y-type CTX-like proteins, are similar to the H-type CTX from cobras. The substitution is conservative though, preserving a less toxic form of elapid CTXlike protein, as indicated by the lack of venom cytotoxicity in previous laboratory and clinical findings. The ecological role of these toxins, however, remains unclear. The study also uncovered unique transcripts that belong to phospholipase $\mathrm{A}_{2}$ of Groups IA and IB, and snake venom metalloproteinases of PIII subclass, which show sequence variations from those of Asiatic elapids.

Conclusion: The venom gland transcriptome of C. bivirgata flaviceps from Malaysia was de novo assembled and annotated. The diversity and expression profile of toxin genes provide insights into the biological and medical importance of the species.

\footnotetext{
* Correspondence: tanch@um.edu.my

https://doi.org/10.1590/1678-9199-JVATITD-2021-0024

Received: 25 February 2021; Accepted: 12 May 2021; Published online: 24 September 2021
} 


\section{Background}

Snake venoms consist of toxins that are primarily proteins and peptides with diverse pharmacological activities [1]. These toxins are products of venom evolution, representing successful traits critical for the survival of various snake species [2]. The evolvability of venom enables the snakes to adapt to different niches and, in turn, facilitates ecological speciation [3]. Worldwide, approximately 300 venomous snake species are considered medically important as they are implicated in snakebite envenomation, a life-threatening condition caused by the venom inoculated in snakebite victims $[4,5]$. It is estimated that $1.8-2.7$ million people are affected by snakebite envenomation, resulting in 81,000 to 138,000 deaths annually $[5,6]$.

In Asia, neurotoxicity is a typical manifestation of envenomation caused by elapid snakes such as cobras, king cobra, kraits and sea snakes. In addition, there is a unique clade of elapids, namely the Asiatic coral snakes, that are often considered less medically important due to their infrequent encounter with human and low fatality rate of envenomation [5]. As such, the venom properties of Asiatic coral snakes are generally less studied in comparison to most other elapids. This limits our understanding of the biological significance and potential application of venoms from these evolutionarily distinct coral snakes in Asia.

The Asiatic (Old World) coral snakes are diverse, comprising three genera, i.e., Calliophis, Hemibungarus and Sinomicrurus [7]. Among these, the blue coral snake (Calliophis bivirgata) is perhaps the most well-known and attractive owing to its unique morphology with striking coloration - its head, tail and underside (ventral surface) are red, and its back is dark blue to black in color flanked by a pair of alluring blue streaks alongside its body [8]. C. bivirgata has a pair of exceptionally long venom glands that extends beyond the jaw distally for one-third the length of the body (Figure 1), and it is ophiophagic (feeding on snakes) [9]. They are often fossorial, hiding beneath rainforest grounds and this makes them very elusive. Although C. bivirgata is often described as reclusive and less aggressive, it can be hostile and ready to bite when provoked. With its extraordinarily long venom glands, an adult $C$. bivirgata can yield a large amount of venom $(\sim 150 \mathrm{mg})$ in a single milking [10], implying potential medical complications upon severe envenomation [11-13].

C. bivirgata is endemic to Southeast Asia and three subspecies are recognized across different localities: C. bivirgata flaviceps in Thailand, Peninsular Malaysia, and Sumatra; C. bivirgata tetrataenia in Borneo; and C. bivirgata bivirgata in Java [14-16] (Figure 1 depicts the native range of the species in Southeast Asia). Among these subspecies, C. bivirgata flaviceps (found in Thailand and Peninsular Malaysia) has been reported to cause human fatalities $[11,12]$. A recent proteomic study showed that Malaysian C. bivirgata flaviceps venom contains high amounts of cytotoxin-like proteins (22.6\%) and phospholipases $\mathrm{A}_{2}$ (41.1\%) which could be instrumental in the pathophysiology of envenomation [15]. Other studies further detected a sodium channel antagonist, a delta-neurotoxin called calliotoxin in $C$. bivirgata venom, indicating that $C$. bivirgata envenomation can potentially result in neurotoxicity $[10,17]$. The $C$. bivirgata venom, however, showed negligible immunological cross-reactivity with
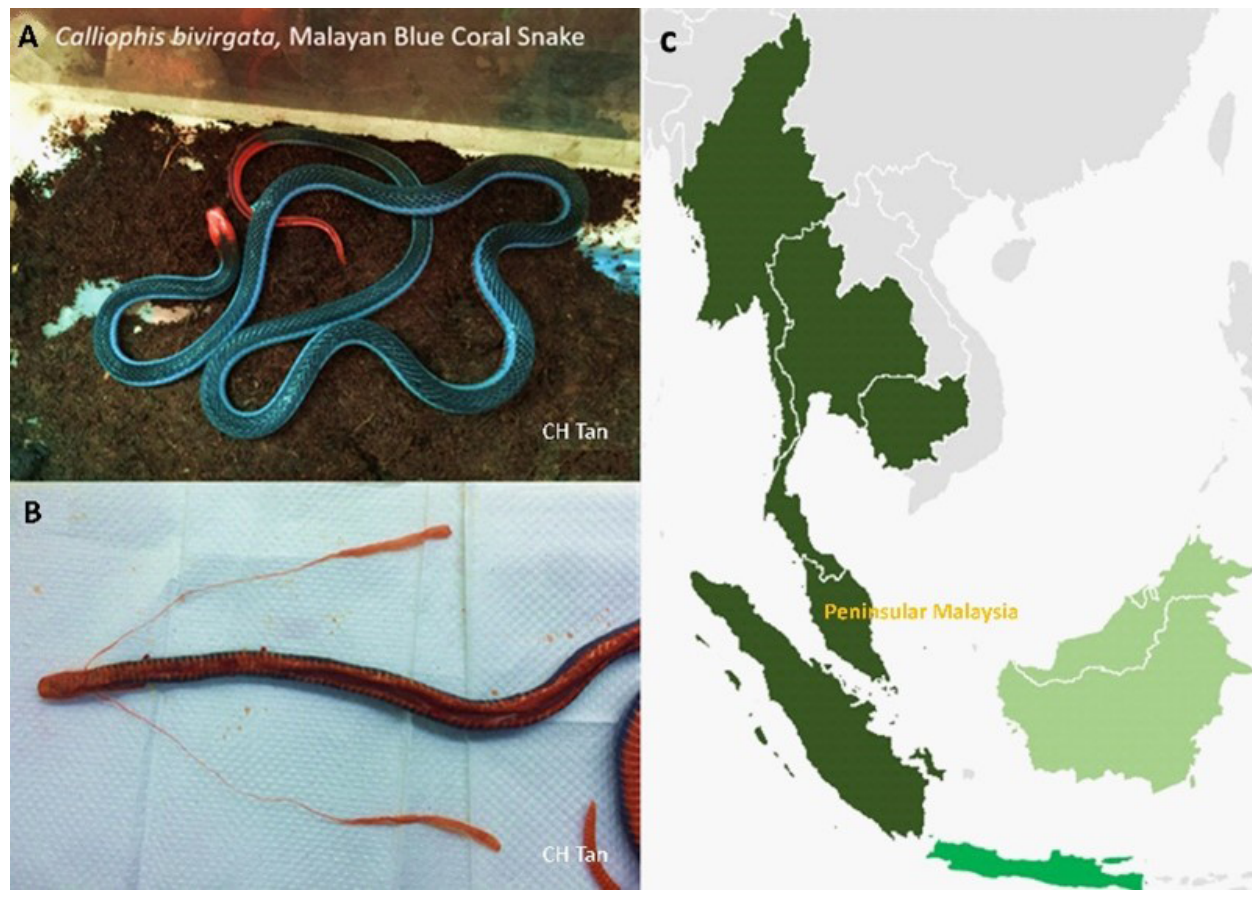

C. bivirgata flaviceps

C. bivirgata bivirgata

C. bivirgata tetrataenia

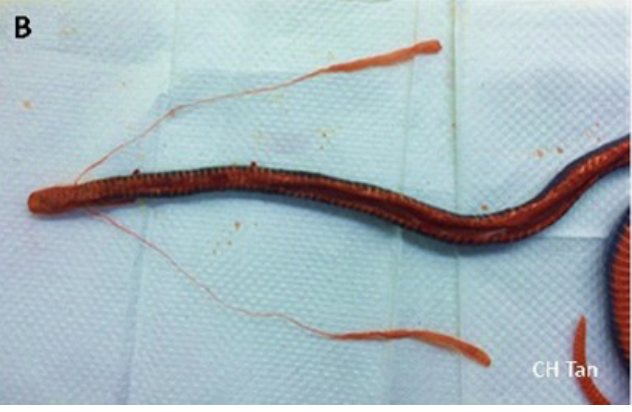

Figure 1. Morphology and distribution of Malayan blue coral snake (Calliophis bivirgata). (A) Dorsal view showing red coloration of the head and tail (which is continuous on the ventral surface), with the back in black or dark blue, flanked by a pair of alluring blue streaks alongside the body. (B) Dissection revealing a pair of exceptionally elongated venom glands in the snake. (C) Areas shaded in green depicting the native distribution of Calliophis subspecies in Southeast Asia based on the Reptile Database [16]. Photos by Choo Hock Tan. 
various elapid antivenoms that were raised against non-coral snake species in Asia, despite having abundant three-finger toxins and phospholipases $\mathrm{A}_{2}$ as the venoms of most other elapid species [18]. These reports unveiled the real hidden threat in $C$. bivirgata envenomation: there is no effective antivenom available to treat the envenomation, and an inappropriate antivenom given to a patient may result in fatal hypersensitive reactions.

The proteome and antigenicity of C. bivirgata venom indicate that the toxin genes of this species are evolutionarily divergent from the other elapids. This has implications on the medical importance of this species in terms of pathophysiology and treatment of envenomation. To better understand the diversity and functions of its toxins, this study investigated the de novo venom gland transcriptome of $C$. bivirgata flaviceps (a subspecies from Peninsular Malaysia) through a high-throughput nextgeneration sequencing approach and deep data mining. In addition, the findings were compared to a recent study of three-finger toxin evolution in this species which also employed the venom gland transcriptomic method [17]. Uncovering the complexity and the diversity of toxin genes in this unique species enriches our current knowledge base of snake venoms, and provides deeper insights into the clinical, biomedical, and evolutionary significance of the Asiatic coral snakes [19].

\section{Methods}

\section{Preparation of snake venom gland tissue}

The Malayan blue coral snake, C. bivirgata flaviceps was a male adult specimen from Pahang in the central region of Peninsular Malaysia. The snake was milked four days before venom gland removal to promote maximal transcription [20]. The venom glands were collected following euthanasia and sectioned into dimensions of $5 \times 5 \mathrm{~mm}$. The sectioned tissue was immersed in RNAlater Solution (Ambion, TX, USA) at $4{ }^{\circ} \mathrm{C}$ overnight followed by $-80^{\circ} \mathrm{C}$ until further use. The study was carried out in line with protocols approved by the Institutional Animal Use and Care Committee (IACUC) of University of Malaya, Malaysia (Approval code: \#2013-11-12/PHAR/R/TCH).

\section{Extraction and purification of total RNA}

The venom gland tissue was homogenized in a $1 \mathrm{ml}$ glass homogenizer with TRIzol solution (Invitrogen, CA, USA), followed by adding $20 \%$ chloroform to separate the RNA (aqueous state) from the DNA and proteins (interface and organic states) [21]. The sample was centrifuged and treated with RNA-free DNAase I (Thermo Fisher Scientific, MA, USA), and the RNA was precipitated with isopropyl alcohol, followed by washing with $70 \%$ ethanol [22]. The quality of the purified total RNA was assessed using Agilent 2100 Bioanalyzer (Agilent RNA 6000 NanoKit) (Agilent Technologies, Waldbronn, Germany). The RNA integrity number of the sample was 8.9 (Grade A), indicating that the quality of RNA was in good condition for further downstream transcriptomic analysis.

\section{Construction of cDNA library}

The cDNA library construction was carried out with MGIEasy RNA Library Prep Set (Item No: 1000006383), as per manufacturer's instructions. In brief, mRNA was purified with Dynabeads mRNA Purification Kit using magnetic beads. Enriched poly $(\mathrm{A})^{+} \mathrm{mRNA}$ isolated from the total venom gland RNA was adopted for cDNA construction. The isolated mRNA was fragmented into short fragments, which acted as templates for cDNA synthesis. Quantitative validation was conducted using ABI StepOnePlus Real-time PCR system (Applied Biosystem, CA, USA), which quantified adaptor-ligated sequences whereas qualitative validation was done using Agilent 2100 Bioanalyzer (Agilent Technologies, Waldbronn, Germany) for quality control of cDNA. The sample was then sequenced in a single lane on the BGISeq-500 platform (BGI Genomics Co., Ltd., Shenzhen, China) with 100-base-pair, paired-end reads.

\section{Filtration of raw sequenced reads}

Sequenced data generated from BGISeq-500 platform were transformed into raw reads in a FASTQ format. Raw reads were filtered as part of the quality control process in the preanalysis stage [23]. Raw reads with unknown bases of more than $5 \%$, reads containing adaptor sequences and low-quality reads which possessed reads containing more than $20 \%$ bases with quality score less than 15 were removed before downstream transcriptome assembly.

\section{Assembly of de novo transcriptome}

The de novo 'shot-gun' transcriptome assembly was performed using a short-reads assembly program, Trinity version 2.0.6, which includes three software modules, Inchworm, Chrysalis, and Butterfly [24, 25], to reconstruct long scaffolds from single reads. Trinity was the assembly method of choice in this study as this program has been shown to recover good transcripts after passing quality filters while also recovering relatively long transcripts at its highest specificity $[26,27]$. The clean read Q20 score, a point of reference for quality control assessment was obtained as a benchmark for successful de novo assembly of the transcriptome.

\section{Clustering of transcripts}

Unigenes obtained from Trinity were processed for sequence splicing and removal of redundant reads utilizing TIGR Gene Indices Clustering Tool (TGICL), version 2.0.6, to isolate nonredundant (NR) transcripts at the longest length [28]. Transcripts that shared nucleotide sequence similarity of more than $70 \%$ were grouped into clusters (transcript ID with the prefix CL labelled as contigs) whereby those sharing less than $70 \%$ similarity were labelled as singletons (transcript ID with a prefix of Unigene).

For functional annotation, all transcripts were subjected to BLASTx (Basic Local Alignment Search Tool-x) applying NCBI non-redundant database (NR), with a cut-off value of $E<10^{-5}$. The coding regions of transcripts were determined by referencing to the highest-ranked proteins. 


\section{Quantifying transcript abundance}

Clean reads were aligned to Unigene using Bowtie2, version 2.2.5 [29]. The gene expression levels were then calculated using RNA-seq with expectation maximization (RSEM) tool, version 1.2.12 [30]. Fragments per kilobase of exon model per million reads mapped (FPKM) were used to determine the transcript abundance for identified genes [31]. FPKM is the summation of normalized read counts based on gene length and the total number of mapped reads. The data was obtained using RSEM tool in conjunction with Trinity based on a computational formula:

$$
\text { FPKM of gene } A=\frac{10^{6} \mathrm{~B}}{N C / 1000}
$$

FPKM is the expression of gene A; B is the number of fragments/reads which are aligned to gene $\mathrm{A} ; \mathrm{N}$ is the total number of fragments/reads that are aligned to all genes; $\mathrm{C}$ is the base number in the coding sequence of gene $\mathrm{A}$.

\section{Categorization of transcripts}

The de novo assembled transcripts were subjected to BLASTx search to obtain the closest resembling sequences from the NR protein database for classification based on functional annotations. The transcripts (Unigenes) were then sifted to remove those with an FPKM value of less than 1, followed by categorization into three groups: "toxins", "non-toxins" and "unidentified" as previously described [32-34] (Additional file 1). "Toxin" transcripts were recruited by toxin-related keywords search against the annotated transcripts $[33,35,36]$. "Nontoxin" and "unidentified" groups contain transcripts of cellular proteins or house-keeping genes, and transcripts that could not be identified, respectively. The redundancy of gene expression was determined by dividing the total FPKM of each group by the total number of transcripts in the respective group of transcripts [34]. In the toxin group, the amino acid sequences were used to further validate the toxin identity through BLASTp suite (Basic Local Alignment Search Tool-Protein) in the UniProtKB (Universal Protein Resource Knowledgebase) database platform. The transcripts were searched against Serpentes database (taxid: 8570) and validated based on the lowest E-score value with the highest percentage of sequence similarity (updated as of March $23,2020)$. The transcripts and sequences, clustered into different toxin families, and information of full-length transcripts, were provided in Additional file 2.

\section{Multiple sequence alignment}

Multiple sequence alignment was conducted using Jalview software (version 2.11.1.4) [37] and MUSCLE (Multiple Sequence Comparison by Log-Expectation) [38] program on amino acid sequences of toxins. Sequences of related species used in multiple sequence alignment were retrieved from UniProtKB depository (http://www.uniprot.org/). The sequences and species selected for comparison were based on toxinological relevance and purpose to elucidate similarity and variation between comparing sequences.

\section{Selection pressure analysis}

Sequences of interest were aligned using Mega X (version 10.0.5). Selection pressure was then analyzed using pairwise distances with amino acid substitution and Maximum Composite Likelihood model. Non-synonymous and synonymous (dN/ dS) substitution rates were obtained.

\section{Results and discussion}

\section{Sequencing and de novo transcriptome assembly}

De novo sequencing of the cDNA library of the Malayan blue coral snake (C. bivirgata flaviceps) venom gland tissue yielded a total of 50,850,478 clean reads. Assembly of the de novo short reads created 79,142 contigs $(\mathrm{N} 50=1,640)$ that were connected to form 52,809 transcripts $(\mathrm{N} 50=1,906)$. Output and quality metrics of RNA sequencing were provided in Additional file 3. The accuracy of sequencing indicative of successful de novo venom gland transcriptome was validated by the base call accuracy of Q20 percentage at 98.53\%.

The transcripts were filtered at the FPKM (fragments per kilobase per million mapped reads) of $\geq 1$ and yielded 35,766 transcripts. Based on BLASTx search, the transcripts were assigned into three categories: (a) "toxin"; (b) "non-toxin"; and (c) "unidentified" (Table 1; Figure 2A). Transcripts in the "toxin" category encoded known and putative snake toxins, and these dominated the transcriptome by a total FPKM of $44.46 \%$. Transcripts in the "non-toxin" category encoded proteins with no known toxic activities in envenomation, and these constituted $40.09 \%$ of the total FPKM. Meanwhile, the "unidentified" category (15.45\% of total FPKM) included transcripts with no identifiable hits from the BLASTx search. The high expression of toxin transcripts (dominating virtually half of the venom gland transcriptome) in the venom gland of this species is consistent with observations reported in Micrurus spp. (American coral snakes) whose toxin gene transcription accounted for $46-61 \%$ of the venom gland transcriptome $[39,40]$.

\section{Expression of toxin genes in C. bivirgata flaviceps venom gland}

A total of 74 distinct transcripts were identified in the "toxin" category. These transcripts were clustered by sequence similarities and relevance of snake venom function into 16 different families of toxin genes (Table 2). Although the total number of all toxin transcripts was only 74, the high expression of all toxins contributed to an exceptionally high redundancy (on average, 5,627.03 FPKM/toxin transcript) in contrast to the much lower levels noted in the non-toxin and unidentified gene groups (19.42 FPKM/transcript and 8.85 FPKM/transcript, respectively) (Figure $2 \mathrm{~A}$ ), consistent with the high activity of toxin gene transcription in the venom gland tissue of the snake.

Out of the 74 toxin transcripts, 31 transcripts have $\geq 90 \%$ sequence coverage based on the annotated protein entries. 
Table 1. Overview of transcript classification and expression in de novo venom gland transcriptome of $C$. bivirgata flaviceps.

\begin{tabular}{lcc}
\hline $\begin{array}{l}\text { Total number of transcripts at fragments per kilobase } \\
\text { of exon model per million mapped reads (FPKM) }>\mathbf{1}\end{array}$ & $\mathbf{3 5 , 7 6 6}$ \\
\hline Categories & Toxin & Non-toxin \\
$\begin{array}{l}\text { Number of transcripts } \\
\text { Relative abundance of transcripts } \\
\text { (\% of total FPKM) }\end{array}$ & 74 & 19,331 \\
Redundancy (average FPKM/transcript) & 44.46 & 40.09 \\
\hline
\end{tabular}
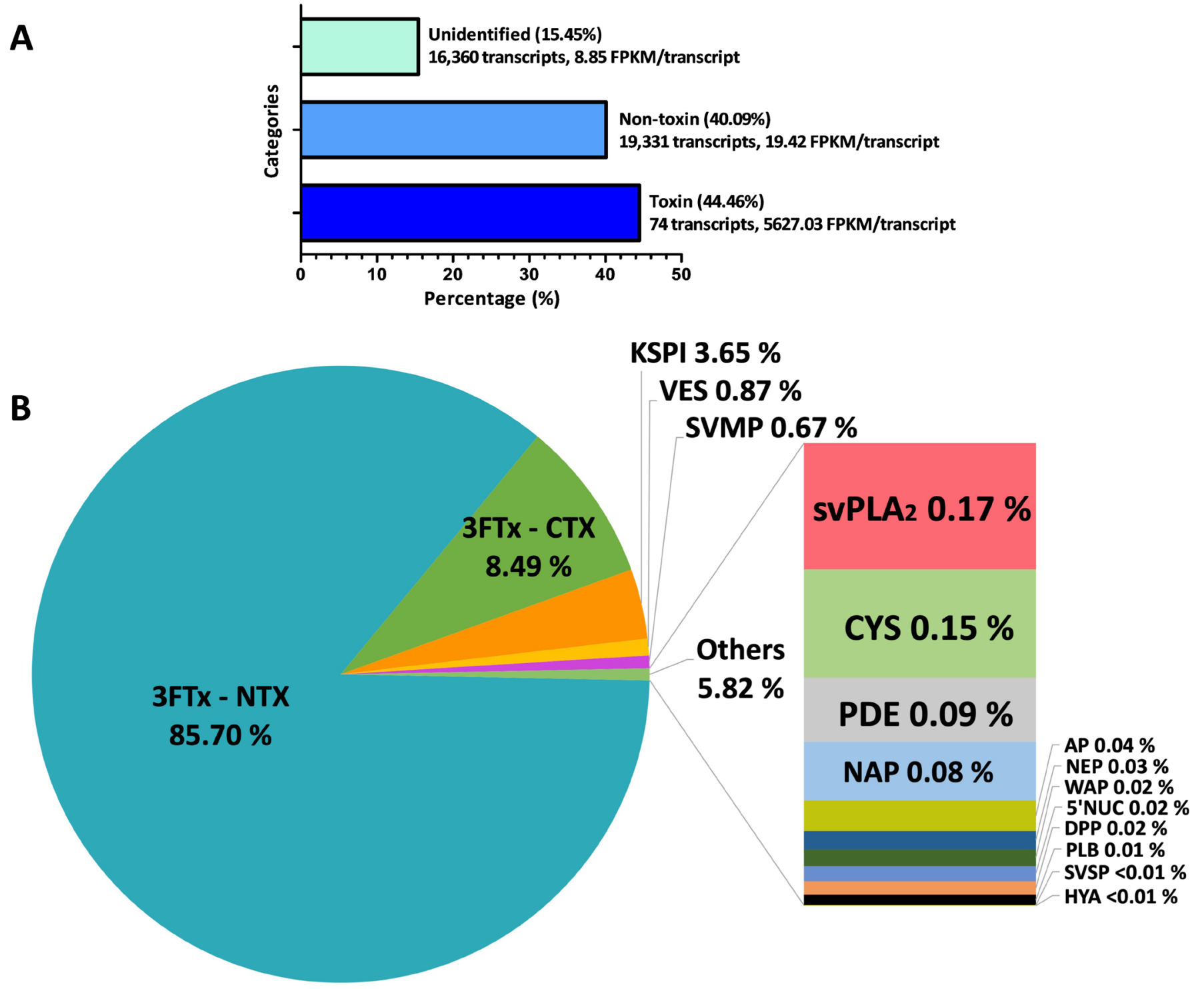

Figure 2. Venom gland transcriptome of Calliophis bivirgata flaviceps from Malaysia. (A) Abundance (in percentage of total FPKM) and redundancy (average FPKM/ transcript) of transcripts according to "toxin", "non-toxin" and "unidentified" categories. (B) Expression profile of toxin transcripts according to protein families (in percentage of total toxin FPKM). The percentages indicate the relative abundances of transcripts based on expression levels in FPKM, as outlined in the method. FPKM: fragments per kilobase of transcript per million mapped reads; 3FTx: three-finger toxin; NTX: neurotoxin; CTX: cytotoxin; KSPI: Kunitz-type serine protease inhibitor; VES: vespryn; SVMP: snake venom metalloproteinase; svPLA $A_{2}$ snake venom phospholipase $A_{2}$; CYS: cystatin; PDE: phosphodiesterase; NAP: natriuretic peptide; AP: aminopeptidase; NEP: neprilysin; WAP: waprin; DPP: dipeptidyl peptidase; 5'NUC: 5'nucleotidase; PLB: phospholipase B; SVSP: snake venom serine protease; HYA: hyaluronidase. 
These toxins were classified under full-length transcripts in the present study (Table 2; sequences available in Additional file 2). The majority of toxin transcripts were annotated based on sequence similarities from various elapid species, while only four transcripts were matched to sequences specific to Calliophis species, indicating that the existing toxin database is indeed limited for the Asiatic coral snakes.

Among the 16 toxin gene families, three-finger toxins (3FTx) are the most diversified and abundantly expressed (20 transcripts at $94.19 \%$ of total toxin FPKM). Its domination in the venom gland transcriptome suggests that the 3FTxs are critical in the venom evolution of $C$. bivirgata flaviceps and implicated in its adaptation to specific ophiophagic diet. The diversely expressed 3FTx genes in this species were further categorized by sequence subtypes into long-chain, short-chain and non-conventional groups (Table 2), and elaborated based on their functional attributes in the context of envenomation. Other toxin families were expressed at much lower levels. These include Kunitz-type serine protease inhibitor (KSPI), vespryn (VES), snake venom metalloproteinase (SVMP), snake venom phospholipase $\mathrm{A}_{2}$ (svPLA ${ }_{2}$ ), cystatin (CYS), phosphodiesterase (PDE), natriuretic peptide (NAP), aminopeptidase (AP), neprilysin (NEP), waprin (WAP), 5 ' nucleotidase (5'NUC), dipeptidyl peptidase (DPP), and phospholipase B (PLB), snake venom serine protease (SVSP) and hyaluronidase (HYA). Figure $2 \mathrm{~B}$ illustrates the overall venom gland transcriptome of $C$. bivirgata flaviceps according to the toxin gene families.

\section{Three-finger toxins (3FTxs)}

3FTxs are typically the major toxins of elapids, e.g., cobras [41, 42], kraits [43, 44], sea snakes [45], mambas [46, 47] and coral snakes [39, 48, 49]. These are non-enzymatic polypeptides with molecular weights of approximately 6-9 kDa, orientated in three beta-stranded loops that resemble three protruding fingers [50, 51]. Comparison of the venom gland transcriptomic profiles between the current study and a recent report [17] reveals a similar dominating pattern of 3FTx, notwithstanding variation in the relative proportions of many toxin subtypes (Table 3). The variation implies potential inter-individual differences between the specimens, e.g., wild versus captive snakes from different geographical regions, or extensive post-translational modifications [52]. Variations also could be accounted for by methodological differences, in terms of tissue harvesting time [20] and program algorithms used in the study. Although transcriptional events in venom gland was shown to achieve the highest level four days after venom extraction [20], the transcriptome may represent only a snapshot of toxin gene expression as different genes likely have varying transcription rates and mRNA half-lives.

Based on the protein structure, 3FTx transcripts in C. bivirgata flaviceps venom gland transcriptome were further categorized into short-chain 3FTx (S-3FTx, with four disulfide bridges), longchain 3FTx (L-3FTx, with an additional fifth disulfide bridge on the second loop) and non-conventional 3FTx (NC-3FTx, with an additional fifth disulfide bridge on the first loop) [51]. Within the 3FTxs family, the most abundantly and diversely expressed transcripts belonged to S-3FTxs (94.16\%, 18 transcripts), while L-3FTx and NC-3FTx each consisted of only one lowly expressed transcript $(<0.05 \%$ of total toxin FPKM) (Table 2). Of these, the majority of S-3FTx transcripts $(40.14 \%$ of toxin FPKM, two transcripts) were annotated by sequence similarities to a deltaneurotoxin, called calliotoxin (UniProtKB: P0DL82). Other S-3FTx composed of 12 putative neurotoxins or neurotoxinlike proteins and four cardiotoxin-like/cytotoxin-like proteins. Multiple sequence alignment revealed highly conserved four disulfide bridges (formed by eight conserved cysteine residues) among the $18 \mathrm{~S}-3 \mathrm{FTx}$, and five disulfide bridges in each of the L-3FTx and NC-3FTx respectively (Figure 3).

\section{Short-chain three-finger toxins (S-3FTxs)}

\section{Delta-neurotoxins (calliotoxin)}

In the venom gland transcriptome, Cb_FTX01 and Cb_FTX02 were the two most abundantly expressed transcripts of S-3FTx. Both transcripts were annotated as calliotoxins (UniProtKB: P0DL82 and Cbivi_3FTx_034 reported by Dashevsky et al. [17]), which is by far the only delta-neurotoxin discovered from snake venoms [10]. To elucidate variation in the genes, sequences of $\mathrm{Cb}_{-}$ FTX01 and Cb_FTX02 were further compared with calliotoxins and representative alpha-neurotoxins from common elapid species found in Southeast Asia (Figure 4). Both Cb_FTX01 and Cb_FTX02 exhibited high sequence similarities (88-100\%) to calliotoxins (UniProtKB: P0DL82) and Cbivi_3FTx_034 [17], suggesting similar pharmacological properties of these delta-neurotoxins expressed in the venom gland transcriptome. An earlier study showed that calliotoxin binds to the sodium channels of motor neurons, prolonging the action potential and resulting in spastic paralysis [10]. The delta-neurotoxin is presumably the principal toxin that causes neurotoxic death in C. bivirgata envenomation, and this neurotoxic effect has been shown to affect different taxa including mammals and birds [10, 15] but resist neutralization by elapid antivenoms [18].

On the other hand, the delta-neurotoxins of C. bivirgata flaviceps lack the specific binding sites toward the alpha-subunit of nicotinic acetylcholine receptor (nAChR) (Lys-27, Trp-29 and Asp-31) [53], and have very low sequence similarity (20-45\%) to elapid alpha-neurotoxins (Figure 4). The emergence of deltaneurotoxin in C. bivirgata flaviceps venom marks the divergent evolution of its 3FTx from virtually all other elapids, whose neurotoxic 3FTxs are primarily alpha-neurotoxins. Alphaneurotoxins block the $\mathrm{AChR}$ and cause flaccid paralysis as the mode of kill, as opposed to spastic paralysis induced by deltaneurotoxins. In nature, delta-neurotoxins are typically present in the venoms of invertebrate animals, e.g., scorpions, solitary wasps, cone snails, spiders, and sea anemone [54-58]. In snakes, thus far, delta-neurotoxins were discovered only from this species. The delta-neurotoxins of C. bivirgata flaviceps, nonetheless, are distinct with only $7-21 \%$ of sequence similarities to those of the 
Table 2. Overview of toxin gene families and subtypes in the venom gland transcriptome of Calliophis bivirgata flaviceps.

\begin{tabular}{|c|c|c|c|}
\hline \multirow{2}{*}{$\begin{array}{l}\text { Toxin gene families/subtypes } \\
\text { Three-finger toxin (3FTx) }\end{array}$} & \multicolumn{2}{|c|}{ Species and annotation based on sequence similarities } & \multirow{2}{*}{$\begin{array}{c}\begin{array}{c}\text { Transcript abundance }^{a} \\
\text { (non-redundant transcript) }\end{array} \\
94.19(20)\end{array}$} \\
\hline & & & \\
\hline Short-chain 3FTx & & & $94.16(18)$ \\
\hline Delta-elapitoxin-Cb1a* & PODL82 & Calliophis bivirgatus & $40.14(2)$ \\
\hline Three-finger toxin MALT0070C & F5CPE6 & Micrurus altirostris & $20.07(3)$ \\
\hline Neurotoxin 3FTx-LI & P0C553 & Bungarus fasciatus & $13.68(3)$ \\
\hline Cytotoxin A5* & P62375 & Naja atra & $7.26(2)$ \\
\hline Neurotoxin 3FTx-RK & P0C554 & Bungarus fasciatus & $5.87(1)$ \\
\hline Three-finger toxin D.L & $\mathrm{AOAOH} 4 \mathrm{BLZ2}$ & Micrurus diastema & $4.63(2)$ \\
\hline Three-finger toxin T.B & $\mathrm{AOAOH} 4 \mathrm{IS} 80$ & Micrurus tener & $1.21(1)$ \\
\hline Maticotoxin A* & P24742 & Calliophis bivirgatus & $1.15(1)$ \\
\hline Cytotoxin homolog $3 *$ & P01473 & Naja melanoleuca & $0.07(1)$ \\
\hline Neurotoxin 3FTx-RI & P0C555 & Bungarus fasciatus & $0.04(1)$ \\
\hline Neurotoxin-like protein NTL2 & Q9W717 & Naja atra & $0.03(1)$ \\
\hline Long-chain 3FTx & & & $0.03(1)$ \\
\hline Long neurotoxin LILong & Q7T213 & Laticauda laticaudata & $0.03(1)$ \\
\hline Non-conventional 3FTx & & & $<0.01(1)$ \\
\hline $\begin{array}{l}\text { Probable weak neurotoxin 3FTx- } \\
\text { Lio1 }\end{array}$ & $\mathrm{A} 7 \times 3 \mathrm{M} 9$ & Erythrolamprus poecilogyrus & $<0.01(1)$ \\
\hline Phospholipase $A_{2}\left(s v P L A_{2}\right)$ & & & $0.17(5)$ \\
\hline Phospholipase $\mathrm{A}_{2} 2^{*}$ & P24645 & Calliophis bivirgatus & $0.08(1)$ \\
\hline Basic phospholipase $A_{2}$ PC17* & Q8UUH8 & Laticauda colubrina & $0.07(2)$ \\
\hline Basic phospholipase $A_{2}$ PC9 & Q8UUH9 & Laticauda colubrina & $0.02(1)$ \\
\hline Group XV phospholipase $A_{2}$ & V8NS07 & Ophiophagus hannah & $<0.01(1)$ \\
\hline \multicolumn{3}{|c|}{ Snake venom metalloproteinase (SVMP) } & $0.67(10)$ \\
\hline Asrin* & A6XJS7 & Austrelaps superbus & $0.50(1)$ \\
\hline $\begin{array}{l}\text { Snake venom metalloproteinase- } \\
\text { disintegrin-like mocarhagin }\end{array}$ & Q10749 & Naja mossambica & $0.10(1)$ \\
\hline $\begin{array}{l}\text { Zinc metalloproteinase- } \\
\text { disintegrin-like MTP4 }\end{array}$ & F8RKW1 & Drysdalia coronoides & $0.04(2)$ \\
\hline $\begin{array}{l}\text { Zinc metalloproteinase- } \\
\text { disintegrin-like ohanin }\end{array}$ & A3R0T9 & Ophiophagus hannah & $0.01(1)$ \\
\hline Nigrescease-1 & B5KFV8 & Cryptophis nigrescens & $0.01(2)$ \\
\hline $\begin{array}{l}\text { Zinc metalloproteinase- } \\
\text { disintegrin-like NaMP* }\end{array}$ & A8QL59 & Naja atra & $<0.01(1)$ \\
\hline $\begin{array}{l}\text { Zinc metalloproteinase- } \\
\text { disintegrin-like BmMP }\end{array}$ & A8QL49 & Bungarus multicinctus & $<0.01(1)$ \\
\hline $\begin{array}{l}\text { Zinc metalloproteinase- } \\
\text { disintegrin-like atragin }\end{array}$ & D3TTC2 & Naja atra & $<0.01(1)$ \\
\hline \multicolumn{3}{|c|}{ Kunitz-type serine protease inhibitor (KSPI) } & $3.65(4)$ \\
\hline $\begin{array}{l}\text { Kunitz-type serine protease } \\
\text { inhibitor mulgin-3 }\end{array}$ & Q6ITB9 & Pseudechis australis & $3.16(1)$ \\
\hline $\begin{array}{l}\text { Kunitz-type serine protease } \\
\text { inhibitor textilinin- } 4\end{array}$ & Q90W98 & Pseudonaja textilis textilis & $0.47(1)$ \\
\hline $\begin{array}{l}\text { Kunitz-type serine protease } \\
\text { inhibitor vestiginin- } 2\end{array}$ & A6MFL2 & Demansia vestigiata & $0.02(1)$ \\
\hline Kunitz-type protease inhibitor $1 *$ & V8N7R6 & Ophiophagus hannah & $0.01(1)$ \\
\hline
\end{tabular}


Table 2. Cont.

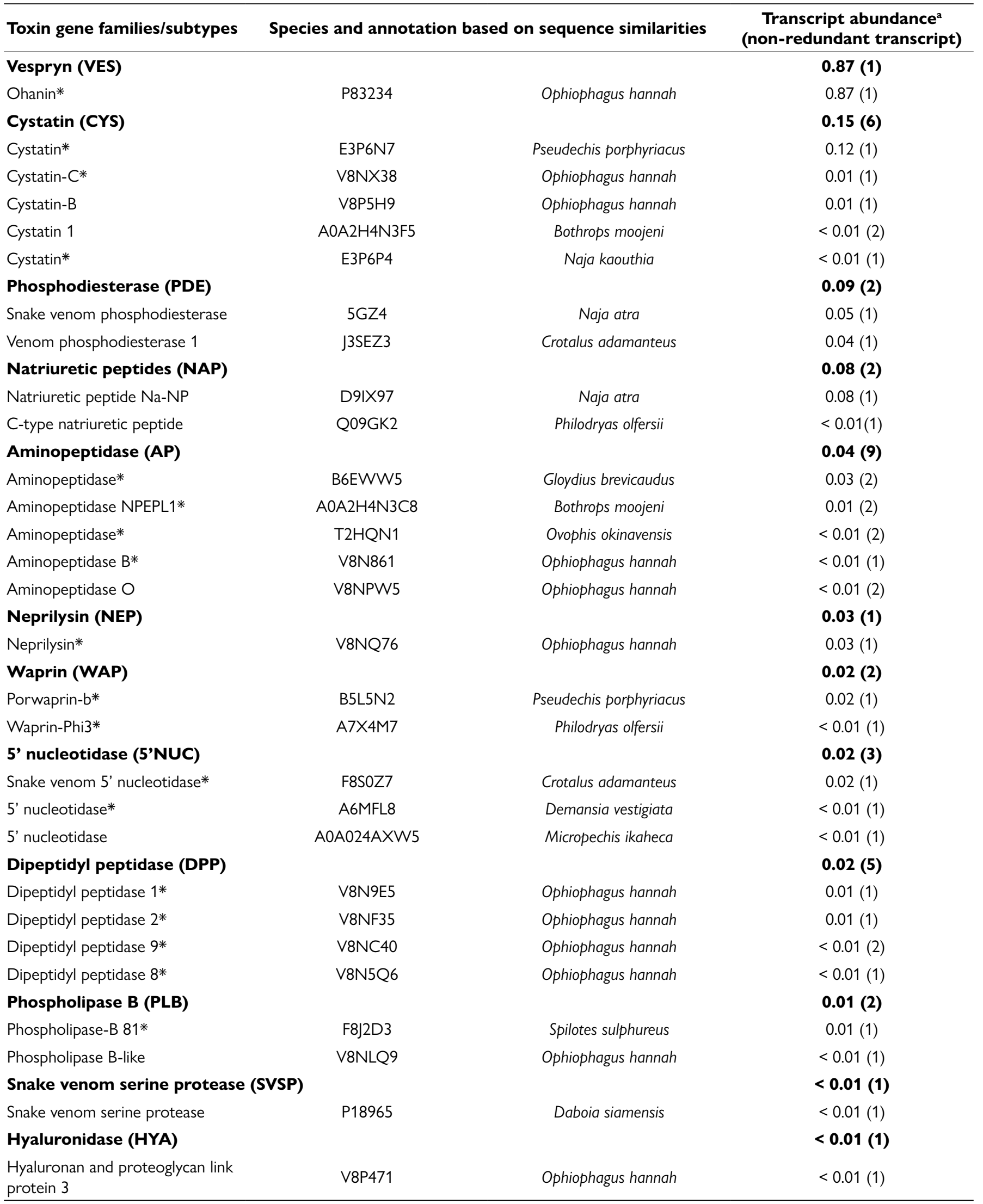

Transcript abundance expression (\%) is based on FPKM (fragments per kilobase of exon model per million reads mapped). *Number of full-length toxin transcripts from venom gland of Calliophis bivirgata flaviceps. Determined by the coverage of amino acids of transcripts to amino acids of mature chain of annotated proteins. 


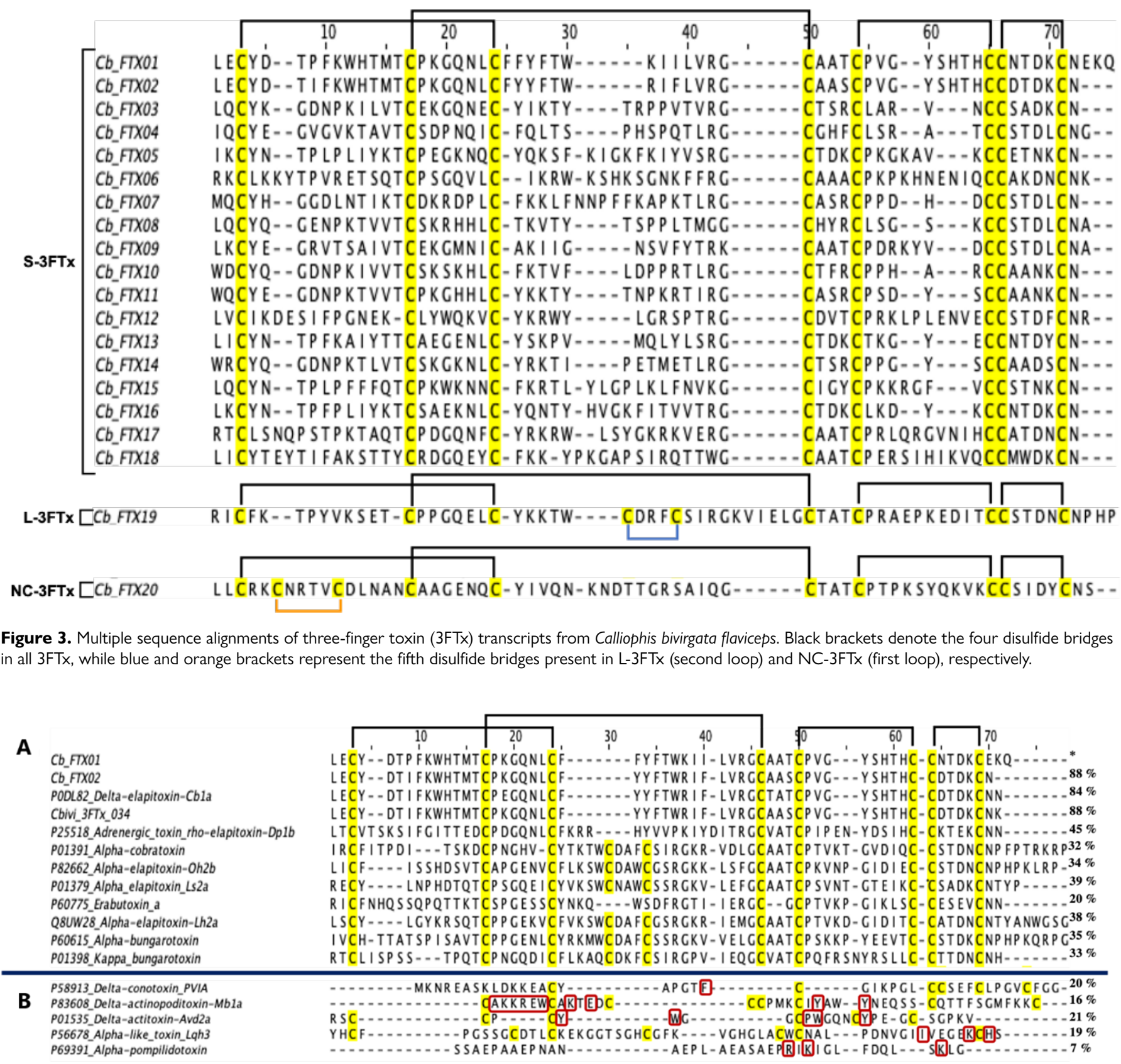

Figure 4. Multiple sequence alignments of Cb_FTX01 and Cb_FTX02 of Calliophis bivirgata flaviceps compared to functionally matched sequences from (A) serpentes and (B) non-serpentes groups obtained from public database. Percentage indicates the sequence similarities compared to Cb_FTX01(*). Black brackets: disulfide bridges, red regions: critical binding amino acid residues.

invertebrate animals. Comparing across different taxa, the deltaneurotoxins of $C$. bivirgata flaviceps are highly divergent from the following invertebrates at their respective critical binding sites: Leiurus hebraeus (UniProtKB: P56678, at Ile-59, Lys-64, His-66) [59]; Anoplius samariensis (UniProtKB: P69391, at Arg1, Lys3 or Lys12) [60]; Conus purpurascens (UniProtKB: P58913, at Phe-60 and Ile-63) [61]; Missulena bradleyi (UniProtKB: P83608, at Lys-3, Lys-4, Arg-5, Glu-6, Trp-7, Lys-10, Glu-12, Tyr-22, Tyr-25) [62]; Anemonia sulcata (UniProtKB: P01535, at Tyr-7, Trp-8, Pro-12, Trp-13 and Tyr-18) [63] (Figure 4). This illustrates a case of functional convergence where C. bivirgata flaviceps and these unrelated species, in their respective biomes, have independently evolved toxins that are functionally similar for the purpose of prey paralyzing.

\section{Cardiotoxin-like/Cytotoxin-like proteins}

Within the S-3FTx group, Cb_FTX05, Cb_FTX13, Cb_FTX15 and Cb_FTX16 are four transcripts encoding for cytotoxinlike/cardiotoxin-like proteins, and accounting for $8.49 \%$ of the total toxin FPKM (Table 3; Additional file 2). Cb_FTX05 and Cb_FTX15 were annotated as cytotoxin (CTX) homologues from Naja atra (UniProtKB: P62375, with 53-55\% similarities), 
Table 3. Comparison of venom gland transcriptomics of the Malayan blue coral snake (Calliophis bivirgata) between two studies.

\begin{tabular}{|c|c|c|}
\hline Toxin gene families & Current study ${ }^{a}$ & Dashevsky et al. [17] \\
\hline Total transcripts & 74 & 125 \\
\hline Three-finger toxins & $20,94.16 \%$ & $67,82 \%$ \\
\hline Neurotoxins & $16,85.70 \%$ & NS \\
\hline Cytotoxin-like proteins & $4,8.49 \%$ & NS \\
\hline Kunitz-type serine protease inhibitor & $4,3.65 \%$ & $24,9 \%$ \\
\hline Phospholipase $A_{2}$ & $5,0.17 \%$ & $13,8 \%$ \\
\hline Vespryn & $\mathbf{1}, 0.87 \%$ & $1, *$ \\
\hline Snake venom metalloproteinase & $10,0.67 \%$ & $4, *$ \\
\hline Cystatin & $6,0.15 \%$ & $4, *$ \\
\hline Phosphodiesterase & $2,<0.1 \%$ & $1, *$ \\
\hline Natriuretic peptide & $\mathbf{2},<0.1 \%$ & NR \\
\hline Aminopeptidase & $9,<0.1 \%$ & NR \\
\hline Neprilysin & $\mathbf{1},<0.1 \%$ & $1, *$ \\
\hline Waprin & $\mathbf{2},<0.1 \%$ & $1, *$ \\
\hline 5’Nucleotidase & $3,<0.1 \%$ & NR \\
\hline Dipeptidyl peptidase & $5,<0.1 \%$ & NR \\
\hline Phospholipase B & $\mathbf{2},<0.1 \%$ & $1, *$ \\
\hline Snake venom serine protease & $1,<0.01 \%$ & NR \\
\hline Hyaluronidase & $\mathbf{1},<0.01 \%$ & $1, *$ \\
\hline Cysteine-rich secretory proteins & NR & $2, *$ \\
\hline Kallikrein & NR & $1, *$ \\
\hline Nerve growth factors & NR & $4, *$ \\
\hline
\end{tabular}

Bold indicates the number of transcripts in each toxin gene family and protein subtype. Percentage indicates the relative abundance of transcripts. ${ }^{\text {a Relative }}$

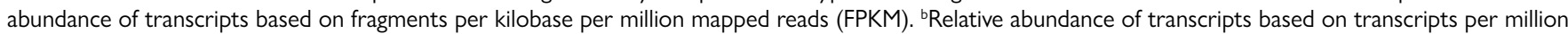
(TPM). *One of the 11 toxin gene families with their total abundance reported as < $1 \%$ collectively. NS: not specified; NR: not reported.

and Cb_FTX16 was annotated as one from Naja melanoleuca (UniProtKB: Q9W716, with 51\% similarity) (Figure 5). Although the CTX-like proteins of $C$. bivirgata flaviceps were annotated as those from cobra (Naja spp.), they were found to have only $\sim 50 \%$ sequence similarity, indicating that the CTX-like proteins of $C$. bivirgata flaviceps are evolutionarily divergent from the cobra CTX, and thus these are purely putative toxins whose activities were hypothesized based on sequence similarities. Significant variations were observed particularly in the loop II region which is critical for CTX binding to the lipid bilayer of membrane [51] (Figure 5), suggesting that the CTX-like proteins of the coral snake are functionally varied from those of cobras.

The other CTX-like transcript, Cb_FTX13, was annotated as maticotoxin (UniProtKB: P24742), a cardiotoxin-like protein reported previously in C. bivirgata venom $[15,64]$. Maticotoxin exhibited weak cytotoxicity in vitro but caused hemolysis in synergistic action with phospholipase $A_{2}[15,64]$. Earlier, in the report by Takasaki et al. [64], maticotoxin was only partially sequenced to 41 amino acid residues with the use of Edman degradation method. The present study, together with the recent study by Dashevsky et al. [17], successfully uncovered its full amino acid sequence and the presence of eight conserved cysteine residues (forming four disulfide bridges) that are responsible for its three-fingered structure (Figure 5). Noteworthy, all CTX-like proteins from C. bivirgata flaviceps represent a unique class not conforming to the usual classification of CTX known presently. Chien et al. [65] through studying the binding effect of various cobra CTX to lipids, proposed that CTX could be divided into P-type and S-type based on the presence of Pro-31 or Ser-29 in the sequence. Both amino acid residues are located within the same phospholipid binding sites in the tip of loop 2, but Ser-29 is located in the more hydrophilic region (thus weaker binding to lipid membrane) [65]. A variant $\mathrm{H}$-type, whose $4^{\text {th }}$ amino acid residue is substituted with histidine, was noted in some CTX regardless of P-type or S-type, and these "H-type" CTX variants are generally less toxic due to weak membrane binding activity [66]. The CTX-like sequences of C. bivirgata flaviceps contain no distinguishable conserved amino acid at residue positions 29 and 31 (neither Ser-29 nor Pro-31) but, interestingly, display conserved tyrosine at the 4 th residue. The emergence of Tyr 4 in these sequences could be probably a result of His substitution by Tyr involving a single nucleotide mutation from $\mathrm{C}$ to $\mathrm{U}$ at the codon (CAU/CAC to UAU/UAC). The mean $\mathrm{dN} / \mathrm{dS}$ ratio comparing the H-type CTX cytotoxin A5 and homolog $5 \mathrm{~V}$ of 


\begin{tabular}{|c|c|}
\hline $\begin{array}{l}\text { P01440_Cytotoxin_2_Naja_naja } \\
\text { P01441_Cytotoxin_2_Naja_oxiana } \\
\text { O93471_Cytotoxin_1_Naja_sputatrix } \\
\text { NSM_FTXO1_Naja_sumatrana }\end{array}$ & \begin{tabular}{l|l|l|l|l|} 
& 10 & 20 & 30 & 50
\end{tabular} \\
\hline $\begin{array}{l}\text { P01442_Cytotoxin_2_Naja_atra } \\
\text { P01443_Cytotoxin_4_Naja_atra } \\
\text { P60305_Cytotoxin_1_Naja_kaouthia } \\
\text { P01451_Cytotoxin_1_Naja_oxiana }\end{array}$ & 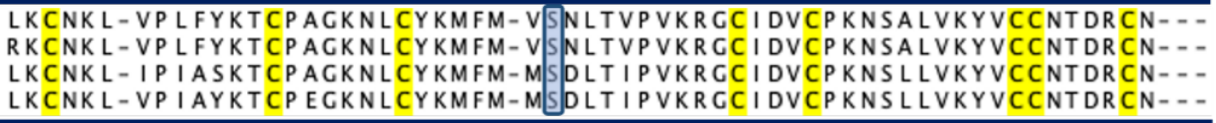 \\
\hline $\begin{array}{l}\text { P62375_Cytotoxin_AS_Naja_atra } \\
\text { Q9W716_Cytotoxin_homolog_SV_Naja_atra } \\
\text { P01474_Cytotoxin_homolog_2_Naja_melanoleuca } \\
\text { P01462_Cytotoxin_2_Naja_annulifera } \\
\text { P01463_Cytotoxin__Naja_nivea } \\
\text { P62394_Cytotoxin_11_Naja_haje_haje }\end{array}$ & 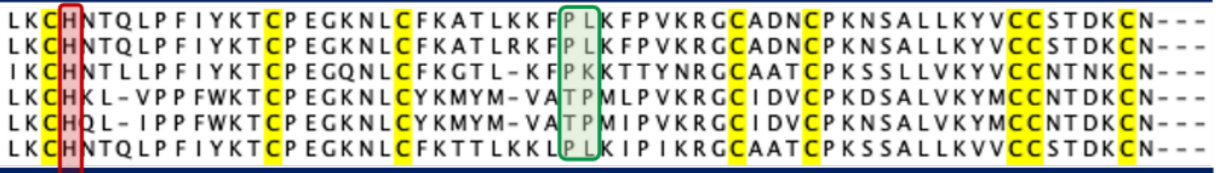 \\
\hline $\begin{array}{l}\text { P01456_Cytotoxin_1_Naja_nivea } \\
\text { P01457_Cytotoxin_S_Naja_haje_haje } \\
\text { P01455_Cytotoxin_1_Naja_annulifera }\end{array}$ & $\begin{array}{l}\text { LKCHKL-VPPVWKTCPEGKNLCYKMFM-VSTSTVPVKRGCI DVCPKDSALVKYVCCSTDKCN--- } \\
\text { LKCHEL-VPPFWKTCPEGKNLCYKMYM-VSSSTVPVKRGCIDVCPKNSALVKYVCCNTDKCN--- } \\
\text { LKCHKL-VPPVWKTCPEGKNLCYKMFM-VSTSTVPVKRGCI DVCPKNSALVKYVCCSTDKCN--- } \\
\end{array}$ \\
\hline $\begin{array}{l}\text { P24742_Maticotoxin_A_Calliophis_bivirgatus } \\
\text { Cb_FTXOS_Calliophis_bivirgatus } \\
\text { Cb_FTX13_Calliophis_bivirgatus } \\
\text { Cb_FTX15_Calliophis_bivirgatus } \\
\text { Cb_FTX16_Calliophis_bivirgatus } \\
\text { Cbivi_3FTX_009_Calliophis_bivirgatus }\end{array}$ & 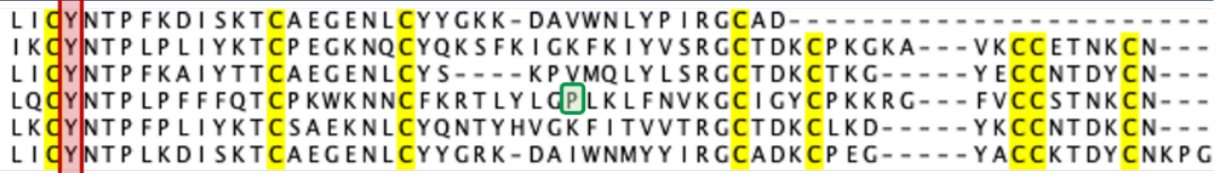 \\
\hline & \\
\hline
\end{tabular}

Figure 5. Multiple sequence alignments of cytotoxin-like transcripts of Calliophis bivirgata flaviceps (Cb_FTX05, -13, $-15,-16)$ aligned and compared to closely related sequences from public database. Highlighted in: red box - His-4/Tyr-4-type; blue box - Ser-28-type, green box - Pro-31-type; black brackets - disulfide bridges.

cobra to the CTX-like proteins of C. bivirgata flaviceps are 0.60 and 0.95 , respectively, implying a synonymous substitution, and that the evolution of the Tyr-4-containing CTX variant is near neutral or under constraint. Considering that His and Tyr were both polar, aromatic and having a positive amino acid substitution similarity score ( +2 based on BLOSUM 62 scoring matrix), the replacement is likely conservative, thus preserving a less cytotoxic form of maticotoxin in the C. bivirgata flaviceps venom $[15,64]$ as with the H-type CTX of cobra [66]. The exact ecological role of the Try-4-containing variants, which we propose as the Y-type CTX/CTX-like proteins of elapid snakes, remains to be further investigated.

\section{Other three-finger toxins (3FTxs)}

A total of 12 transcripts, constituting $45 \%$ of the toxin FPKM, were annotated to various neurotoxin-related genes (Table 4). These transcripts were matched with limited sequence similarities mainly to S-3FTXs reported from coral snakes (Micrurus spp.), cobras (Naja spp.), kraits (Bungarus spp.) and sea krait (Laticauda spp.). Notably, most of these transcripts were only present at the mRNA level (present study) but not detected in the venom proteome reported earlier [15], suggesting a complex regulatory process between gene transcription and protein translation. Some of the transcripts probably undergo rapid degradation, pre-empting meaningful translation as in pseudogenization - a more common fate for a duplicated gene, which would have been anticipated in the course of evolution of the extended 3FTx gene family in this species. Are these representations of pseudogenes conserved among the elapids, evolving free of selective pressure and following random genetic drift? Regardless, these minor proteins if translated in the venom would be toxins that potentially play an integral role in the overall venom function. The biological function and pathophysiological roles of these toxins, nevertheless, deserve further investigation in the future.

\section{Snake venom phospholipases $A_{2}$ (svPLA s $_{2}$}

Snake venom phospholipases $\mathrm{A}_{2}$ are extensively distributed in the venoms of virtually all snake species, although recent studies revealed exceptions in the venoms of African non-spitting cobras (subgenus: Uraeus) [70,71]. Conventionally, snake venom $\mathrm{PLA}_{2}\left(\right.$ svPLA $_{2}$ ) are classified into the secretory svPLA family of Groups IA (cobras and kraits), IIA (most viperids) and IIB (Gaboon vipers) [72]. In the C. bivirgata flaviceps venom gland transcriptome, a total of five svPLA transcripts (Cb_PLA01-05, $0.17 \%$ of total toxin FPKM) were identified (Table 2; Additional file 2). Of these, the full-length transcripts of the two main svPLA 2 (Cb_PLA01 and Cb_PLA02) were characterized, and categorized as Group IB and Group IA svPLA, respectively. Conserved amino acid residues His-48, Tyr-52 and Asp-99 in svPLA $_{2}$ [72] were present in the svPLA transcripts of $C$. bivirgata flaviceps. In addition to these critical amino acid residues, these svPLA transcripts contain Asp-49 which is one of the key residues for enzymatic activities [73]. Similarly, Cb_PLA01 and transcripts retrieved from another study (Cbivi_PLA2_00, -03, -07 and -09) [17] contain a surface loop located between residues 62 to 66, termed pancreatic loop, which is a characteristic of Group IB svPLA 2 [74] (Figure 6). Group IB svPLA, mainly found in mammalian pancreas, have been reported in only a few snake venoms from elapids such as Oxyuranus scutellatus [75], Pseudonaja textilis [76] and Micrurus frontalis frontalis [77]. The 
Table 4. Other putative neurotoxins in C. bivirgata flaviceps venom gland transcriptome.

\begin{tabular}{|c|c|c|c|c|c|}
\hline Toxin transcripts & Toxin subtypes & $\begin{array}{l}\text { Annotated } \\
\text { sequences } \\
\text { and species }\end{array}$ & Reference & $\begin{array}{c}\text { Sequence } \\
\text { similarities (\%) }\end{array}$ & $\begin{array}{c}\text { Toxin FPKM } \\
\text { (\%) }\end{array}$ \\
\hline \multicolumn{6}{|c|}{ Short-chain three-finger toxins } \\
\hline $\begin{array}{l}\text { Cb_FTX03 } \\
\text { Cb_FTX08 } \\
\text { Cb_FTX09 }\end{array}$ & Three-finger toxin MALT0070C & $\begin{array}{c}\text { F5CPE6, } \\
\text { Micrurus altirostris }\end{array}$ & [39] & $\begin{array}{l}42 \\
41 \\
41\end{array}$ & 20.1 \\
\hline $\begin{array}{l}\text { Cb_FTX04 } \\
\text { Cb_FTX07 } \\
\text { Cb_FTX14 }\end{array}$ & Neurotoxin 3FTx-LI & $\begin{array}{c}\text { P0C553, } \\
\text { Bungarus fasciatus }\end{array}$ & {$[67]$} & $\begin{array}{l}41 \\
43 \\
42\end{array}$ & 13.7 \\
\hline Cb_FTX06 & Neurotoxin 3FTx-RK & $\begin{array}{c}\text { P0C554, } \\
\text { Bungarus fasciatus }\end{array}$ & [68] & 65 & 5.9 \\
\hline $\begin{array}{l}\text { Cb_FTX10 } \\
\text { Cb_FTX11 }\end{array}$ & Three-finger toxin D.L & $\begin{array}{l}\text { AOAOH4BLZ2, } \\
\text { Micrurus diastema }\end{array}$ & Uncharacterized & $\begin{array}{l}42 \\
45\end{array}$ & 4.6 \\
\hline Cb_FTX12 & Three-finger toxin T.B & $\begin{array}{l}\text { AKO63249, } \\
\text { Micrurus tener }\end{array}$ & Uncharacterized & 55 & 1.2 \\
\hline Cb_FTX17 & Neurotoxin_3FTx-RI & $\begin{array}{c}\text { P0C555, } \\
\text { Bungarus fasciatus }\end{array}$ & {$[67]$} & 44 & $<0.1$ \\
\hline Cb_FTX18 & Neurotoxin-like protein NTL2 & $\begin{array}{l}\text { Q9W717, } \\
\text { Naja atra }\end{array}$ & Uncharacterized & 44 & $<0.1$ \\
\hline \multicolumn{6}{|c|}{ Long-chain three-finger toxins } \\
\hline Cb_FTX19 & Long neurotoxin LILong & $\begin{array}{c}\text { Q7T213, } \\
\text { Laticauda laticaudata }\end{array}$ & [69] & 93 & $<0.1$ \\
\hline \multicolumn{6}{|c|}{ Non-conventional three-finger toxins } \\
\hline Cb_FTX20 & $\begin{array}{c}\text { Probable weak } \\
\text { neurotoxin 3FTx-Lio1 }\end{array}$ & $\begin{array}{c}\text { A7X3M9, } \\
\text { Erythrolamprus } \\
\text { poecilogyrus }\end{array}$ & Uncharacterized & 60 & $<0.1$ \\
\hline
\end{tabular}

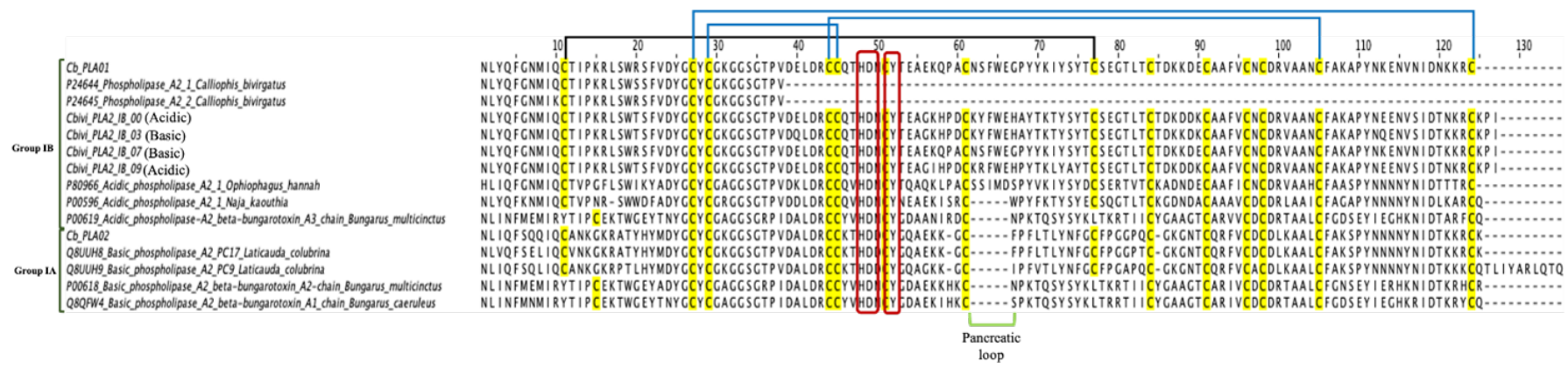

Figure 6. Multiple sequence alignment of snake venom phospholipase $A_{2}$ (svPLA $A_{2}$ ) transcripts (Cb_PLA01 and Cb_PLA02) of Calliophis bivirgata flaviceps aligned and compared to closely related sequences from public database. Brackets in blue and green: conservative disulfide bonds and residues of pancreatic loop; black: additional disulfide bridges; red box: conserved amino acid residues.

presence of the hydrophilic pancreatic loop in Group IB svPLA has been shown to decrease the substrate-PLA 2 enzyme binding activity [74], but the biological significance of this phenomenon and its effect on snakebite envenomation remain unclear. In comparison, Cb_PLA01 exhibited high sequence similarities to Cbivi_PLA2_00,-03,-07 and -09 (86-99\% sequence similarities), suggesting they may exhibit similar pharmacological activities. It is also notable that Group IA svPLA (Cb_PLA02) was absent in the recently reported study of the same species [17].
Based on the computation determination of theoretical pI (isoelectrical point) using ExPASy computational tool (SIB Swiss Institute of Bioinformatics), Cb_PLA01, Cbivi_PLA2_IB_00 and Cbivi_PLA2_IB_09 isoforms were found to be acidic (pI: 6.70, 5.88 and 5.88, respectively) whereas Cb_PLA02, Cbivi_PLA2_ IB_03 and Cbivi_PLA2_IB07 isoforms were basic (pI: 8.75, 8.19 , and 7.53, respectively). On multiple sequence alignment, Cb_PLA01 were annotated as acidic svPLA from Ophiophagus hannah (UniProtKB: P80966) and Naja kaouthia (UniProtKB: 
P00596) with sequence similarities of $\sim 70 \%$ (Figure 6). An acidic svPLA $A_{2}$ from king cobra was previously reported to cause myocardial and skeletal muscle degeneration in mice [78], while acidic svPLA from other elapids generally lack toxicity $[45,79,80]$. On the other hand, Cb_PLA02 (coding for a basic svPLA 2 ) showed $\sim 90 \%$ sequence similarity to two basic svPLA 2 isoforms from the sea krait, Laticauda colubrina (UniProtKB: Q8UUH8 and Q8UUH9) (Figure 6). Multiple sequence alignment in Figure 6 further revealed that both svPLA transcripts (CB_PLA01 and CB_PLA02) have limited sequence similarity (45-50\%) to the pre-synaptic beta-bungarotoxins from Bungarus spp. (kraits), which are also ophiophagic venomous snakes found in Asia. The finding is consistent with transient myotoxicity and the lack of presynaptic neurotoxic activity caused by C. bivirgata flaviceps venom $[15,64]$.

\section{Snake venom metalloproteinase (SVMP)}

Snake venom metalloproteinases (SVMP) are multi-domain proteins with diverse biological activities, e.g., causing hemorrhage, fibrinogenolysis and defibrination, and inhibition of platelet aggregation [81]. These proteins are usually major components in the venoms of vipers and pit vipers, consistent with the pathological phenotypes seen in viper/pit viper envenomation (hemorrhagic syndrome and consumptive coagulopathy) [82]. Most elapid venoms contain little or small amount of SVMP, with the exceptions of king cobra [32] and Asian coral snakes (Calliophis spp.) $[15,17,49]$. The biological and pathological role of SVMP in elapid venoms has not been well elucidated although it could be contributing to inflammatory responses [83]. Interestingly, elapid SVMP are commonly members of PIII class which are more structurally and functionally variable [84]. In the case of $C$. bivirgata flaviceps venom gland transcriptome, a total of eight transcripts of SVMP, with two of which showing full-length sequences (Cb_SVMP01 and Cb_SVMP07), were identified at a very low abundance ( $0.7 \%$ of total toxin FPKM) (Table 2; Additional file 2).

All the transcripts from the present work and a recent study [17] belong to PIII class of SVMP in which the mature chain of protein consists of the metalloproteinase, disintegrin-like, and cysteine-rich domains, with conserved ECD (glutamic acid, cysteine, aspartic acid) integrin-binding motifs present at the disintegrin domain (Figure 7). In comparison, Cb_SVMP01 showed high sequence similarities (82-94\%) to transcripts Cbivi_SVMP02,-06, -07 and -11 (Figure 7) [17]. On BLAST search, the SVMP sequences of $C$. bivirgata flaviceps matched most closely to those from cobras (Naja spp.) but with limited sequence similarity (56-75\%) (Figure 7), suggesting molecular and perhaps functional adaptation in SVMP that is unique to the Asiatic coral snake and divergent from the cobras.

\section{Other minor toxin transcripts}

Other toxin genes with low expression ( $<5 \%$ of toxin FPKM) include Kunitz-type serine protease inhibitor (KSPI), vespryn (VES), cystatin (CYS), phosphodiesterase (PDE), natriuretic peptide (NAP), aminopeptidase (AP), neprilysin (NEP), waprin (WAP), 5'nucleotidase (NUC), dipeptidyl peptidase (DPP), phospholipase B (PLB), snake venom serine protease (SVSP) and hyaluronidase (HYA). Among these, VES, CYS, PDE, NUC and HYA were previously reported in the venom proteome at low abundances [15]. In contrast, the other toxin families, i.e., KSPI, NAP, AP, NEP, WAP, DPP, PLB and SVSP were not found in the venom proteome, presumably due to their very low protein abundances below the detection limit of the mass spectrometry used. From the venom gland transcriptomics, the findings suggest that the toxin genes are conserved in the Calliophis lineage.

Meanwhile, a discrepancy was observed between the transcript expression level (present study) and protein abundance in the venom proteome reported previously [15]. The lack of correlation between toxin gene expression and venom protein abundance has also been reported in several earlier studies [32, 33, 39, 40, 85]. It should be noted that in most venom gland transcriptomic studies, the venom gland transcriptome reflects a "snapshot" of gene expression at a certain time point when the gland tissue was harvested, typically a few days after venom milking. The mRNAs of various toxins could be expressed at different rates, having varying half-lives and subjected to complex regulation processes including post-transcriptional and post-translational modifications [86]. These events in between could have further modulated the maturation and secretion of proteins into the final venom product, thus the lack of correlation between the transcript expression and protein abundance. Furthermore, the

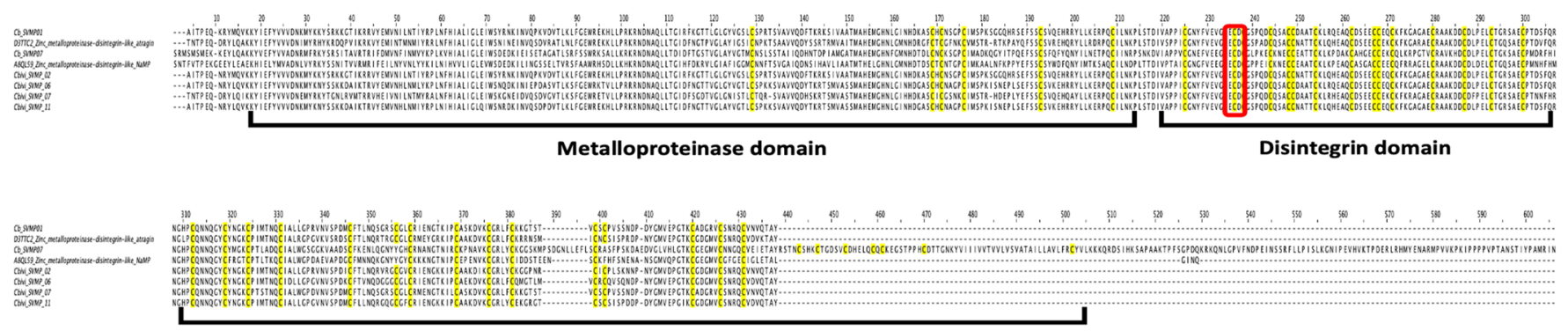

Cysteine-rich domain

Figure 7. Multiple sequence alignment of snake venom metalloproteinase (SVMP) transcripts (Cb_SVMP01 and Cb_SVMP07) of Calliophis bivirgata flaviceps with other annotated sequences. Brackets in black: metalloproteinase, disintegrin and cysteine-rich domains; red regions: ECD motif. 
use of a single de novo assembly program (Trinity) is a limitation in this study, as ideally a combination of multiple assemblers may have added advantage to fully capture the entirety of the transcripts expressed [26]. Nevertheless, Trinity (assembler program used in this study) is one that has been widely applied in venom-gland transcriptomics, and it has been shown to recover the highest number of good transcripts that passed quality filters $[26,27]$.

Furthermore, while calliotoxin (a delta-neurotoxin) has been identified in the present transcriptomic study and from the venom of the homologous Malaysian species [10], this unique toxin was not detected in the venom proteomics reported earlier [15]. Previously, the toxin was not detected in the venom proteome presumably due to the lack of the complete sequence back then to support a comprehensive reference search database. The proteomic approach adopted was deriving quantitative information from peptide-centric mass spectrometry data, which has its weakness in protein identification without a model organism to provide a reference database with complete sequence coverage. In regard to this, we propose that the venom proteome can be re-investigated using a more comprehensive database, incorporating the diverse species-specific toxin sequences including the calliotoxin isolated by Yang et al. [10], and de novo sequences from the recent study [17] and current work.

\section{Conclusion}

To summarize, this study reported the de novo venom gland transcriptomics of Calliophis bivirgata flaviceps, a unique Asiatic coral snake species from the Peninsula of Malaysia. The findings unveiled the complexity and diversity of venom genes in the species, demonstrating inter-specific and intra-specific variations in the sequences and expressions of toxin genes. Of note, threefinger toxins uncovered from this species show remarkable variability in their sequences and putative functions from those of many Asiatic elapids, as indicated by the presence of deltaneurotoxins (including calliotoxin), Tyr-4-containing CTX-like proteins, svPLA 2 of Group IA and IB, and divergent forms of PIII class of SVMP. The findings enriched the toxin knowledge base for the Malayan blue coral snake, and the comprehensive transcriptomic profiling provides deeper insights into the medical and biological significance of the species.

\section{Abbreviations}

cDNA: complementary deoxyribonucleic acid; 3FTx: three-finger toxin; CTX: cytotoxin; C. bivirgata: Calliophis bivirgata; C. bivirgata flaviceps: Calliophis bivirgata flaviceps; FPKM: fragments per kilobase per million mapped reads; BLAST: basic local alignment search tool; KSPI: Kunitz-type serine protease inhibitor; VES: vespryn; SVMP: snake venom metalloproteinase; svPLA ${ }_{2}$ : snake venom phospholipase $\mathrm{A}_{2}$; CYS: cystatin; PDE: phosphodiesterase; NAP: natriuretic peptide; AP: aminopeptidase; NEP: neprilysin; WAP: waprin; 5’NUC: 5' nucleotidase; DPP: dipeptidyl peptidase;
PLB: phospholipase B; SVSP: snake venom serine protease; HYA: hyaluronidase; NTX: neurotoxin; TPM: transcript per million; ND: not detected; NS: not specified; S-3FTx: short three-finger toxin; L-3FTx: long three-finger toxin; NC-3FTx: non-conventional three-finger toxin; $\mathrm{nAChR}$ : nicotinic acetylcholine receptor; mRNA: messenger ribonucleic acid; spp.: species pluralis; IACUC: Institutional Animal Use and Care Committee; RNA: ribonucleic acid; PCR: polymerase chain reaction; NCBI: National Centre for Biotechnology Information; NR: non-redundant; RSEM: RNA-seq with expectation maximization; BLASTp: Basic Local Alignment Search Tool-Protein; UniProtKB: Universal Protein Resource Knowledgebase; MUSCLE: Multiple Sequence Comparison by Log-Expectation.

\section{Availability of data}

Sequencing data from the de novo venom gland transcriptomics of Calliophis bivirgata flaviceps was deposited in National Centre for Biotechnology Information (NCBI) Sequence Read Archive (http://submit.ncbi.nlm.nih.gov) under SRA accession: PRJNA639409.

\section{Availability of data and materials}

Not applicable.

\section{Funding}

The present study was supported by the University of Malaya (Grant numbers: BKS003-2020 and ST011-2020).

\section{Competing interests}

The authors declare that they have no competing interests.

\section{Authors' contributions}

CHT and KYT conceptualized and designed the study. CHT and PP performed the experiments. PP analyzed the data. PP wrote the main manuscript. CHT and KYT revised manuscript draft. All authors read, revised, and approved the final manuscript.

\section{Ethics approval}

The study was carried out in accordance with the protocols approved by the Institutional Animal Use and Care Committee (IACUC) of University of Malaya, Malaysia (Approval code: \#2013-11-12/PHAR/R/TCH).

\section{Consent for publication}

Not applicable.

\section{Supplementary material}

Additional file 1. Venom gland transcriptomic analysis of Calliophis bivirgata flaviceps. 
Additional file 2. Classification and sequences of toxin genes from Calliophis bivirgata flaviceps venom gland transcriptome.

Additional file 3. Output and quality metrics of RNA sequencing for the de novo assembly of Calliophis bivirgata flaviceps venom gland transcriptome.

\section{References}

1. Casewell NR, Wüster W, Vonk FJ, Harrison RA, Fry BG. Complex cocktails: the evolutionary novelty of venoms. Trends Ecol Evol. 2013;28(4):219-29. doi: 10.1016/j.tree.2012.10.020. PubMed PMID: 23219381.

2. Kordis D, Gubensek F. Adaptive evolution of animal toxin multigene families. Gene. 2000 Dec 30;261(1):43-52. doi: 10.1016/s0378-1119(00)00490-x. PubMed PMID: 11164036.

3. Wollenberg Valero KC, Marshall JC, Bastiaans E, Caccone A, Camargo A, Morando M, Niemiller ML, Pabijan M, Russello MA, Sinervo B, Werneck FP, Sites Jr JW, Wiens JJ, Steinfartz S. Patterns, mechanisms and genetics of speciation in reptiles and amphibians. Genes (Basel). 2019 Aug 26;10(9):646. doi: 10.3390/genes10090646. PubMed PMID: 31455040.

4. Gutiérrez JM, Calvete JJ, Habib AG, Harrison RA, Williams DJ, Warrell DA. Snakebite envenoming. Nat Rev Dis Primers. 2017 Sep 14;3:17063. doi: 10.1038/nrdp.2017.63. PubMed Central PMCID: 28905944.

5. World Health Organization. Guidelines for the management of snakebites. 2nd ed. WHO Regional Office for South-East Asia; 2016:1-204. Available from: https://apps.who.int/iris/handle/10665/249547.

6. Kasturiratne A, Wickremasinghe AR, de Silva N, Gunawardena NK, Pathmeswaran A, Premaratna R, Savioli L, Lalloo DG, de Silva HJ. The global burden of snakebite: a literature analysis and modelling based on regional estimates of envenoming and deaths. PLoS Med. 2008 Nov 4; 5(11):e218. doi: 10.1371/journal.pmed.0050218. PubMed PMID: 18986210; PubMed Central PMCID: PMC2577696.

7. Slowinski JB, Boundy J, Lawson R. The phylogenetic relationships of Asian coral snakes (Elapidae: Calliophis and Maticora) based on morphology and molecular characters. Herpetol. 2001;57(2):233-45.

8. Chanhome L, Cox MJ, Vasaruchapong T, Chaiyabutr N, Sitprija V. Characterization of venomous snakes of Thailand. Asian Biomed. 2011 Jun;5(3):311-28.

9. Stuebing RB, Inger RF, Lardner B. A field guide to the snakes of Borneo. 2nd ed. Borneo: Natural History Publications; 2014.

10. Yang DC, Deuis JR, Dashevsky D, Dobson J, Jackson TNW, Brust A, Xie B, Koludarov I, Debono J, Hendrikx I, Hodgson WC, Josh P, Nouwens A, Baillie GJ, Bruxner TJ, Alewood PF, Lim KKP, Frank N, Vetter I, Fry $B G$. The snake with the scorpion's sting: novel three-finger toxin sodium channel activators from the venom of the long-glanded blue coral snake (Calliophis bivirgatus). Toxins (Basel). 2016 Oct 18;8(10):303. doi: 10.3390/ toxins8100303. PubMed PMID: 27763551; PubMed Central PMCID: PMC5086663.

11. Harrison JL. The bite of blue Malaysian coral snake or Ular Matahari (Maticora bivirgata). Malayan Nat J. 1957;11(4):130-2.

12. Lim FLK, Lee MTM. Fascinating snakes in Southeast Asia: an introduction raffles bulletin of zoology. Kuala Lumpur: Tropical Press Sdn. Bhd.; 1990.

13. Lim KKP, Lim FLK. A guide to the amphibians and reptiles of Singapore. 1st ed. Singapore: Singapore Science Centre; 1992.

14. Grismer L, Chan-Ard T. Calliophis bivirgata. 2012. In: The IUCN Red List of Threatened Species 2012 [Internet]. doi: dx.doi.org/10.2305/IUCN. UK.2012-1.RLTS.T191956A2020812.en.

15. Tan CH, Fung SY, Yap MKK, Leong PK, Liew JL, Tan NH. Unveiling the elusive and exotic: venomics of the Malayan blue coral snake (Calliophis bivirgata flaviceps). J Proteomics. 2016 Jan 30;132:1-12. doi: 10.1016/j. jprot.2015.11.014. PubMed PMID: 26598790.

16. The Reptile Database [Internet].Ostrava (Czech Republic): Reptarium. 1995-. Calliophis bivirgatus (BOIE, 1827); [cited 2021 July 20]; [about 3 screens]. Available from: https://reptile-database.reptarium.cz/species? genus=Calliophis\&species=bivirgatus.
17. Dashevsky D, Rokyta D, Frank N, Nouwens A, Fry BG. Electric blue: molecular evolution of three-finger toxins in the long-glanded coral snake species Calliophis bivirgatus. Toxins (Basel). 2021 Feb 8;13(2):124. doi: 10.3390/toxins13020124. PubMed PMID: 33567660.

18. Tan CH, Liew JL, Tan KY, Tan NH. Genus Calliophis of asiatic coral snakes: a deficiency of venom cross-reactivity and neutralization against seven regional elapid antivenoms. Toxicon. 2016 Oct;121:130-3. doi: 10.1016/j. toxicon.2016.09.003. PubMed PMID: 27616455.

19. Brahma RK, McCleary RJR, Kini RM, Doley R. Venom gland transcriptomics for identifying, cataloging, and characterizing venom proteins in snakes. Toxicon. 2015 Jan;93:1-10. doi: 10.1016/j.toxicon.2014.10.022. PubMed PMID: 25448392

20. Rotenberg D, Bamberger ES, Kochva E. Studies on ribonucleic acid synthesis in the venom glands of vipera palaestinae (Ophidia, Reptilia). Biochem J. 1971 Feb;121(4):609-12. doi: 10.1042/bj1210609. PubMed PMID: 4940047; PubMed Central PMCID: PMC1176636.

21. Rio DC, Ares Jr M, Hannon GJ, Nilsen TW. Purification of RNA using TRIzol (TRI reagent). Cold Spring Harb Protoc. 2010 Jun;2010(6):pdb. prot5439. doi: 10.1101/pdb.prot5439. PubMed PMID: 20516177.

22. Rio DC, Ares Jr M, Hannon GJ, Nilsen TW. Ethanol precipitation of RNA and the use of carriers. Cold Spring Harb Protoc. 2010 Jun;2010(6): pdb. prot5440. doi: 10.1101/pdb.prot5440. PubMed PMID: 20516178.

23. Conesa A, Madrigal P, Tarazona S, Gomez-Cabrero D, Cervera A, McPherson A, Szcześniak MW, Gaffney DJ, Elo LL, Zhang X, Mortazavi A. A survey of best practices for RNA-seq data analysis. Genome Biol. 2016 Jan 26;17:13. doi: 10.1186/s13059-016-0881-8. PubMed PMID: 26813401; PubMed Central PMCID: PMC4728800.

24. Grabherr MG, Haas BJ, Yassour M, Levin JZ, Thompson DA, Amit I, Adiconis X, Fan L, Raychowdhury R, Zeng Q, Chen Z, Mauceli E, Hacohen N, Gnirke A, Rhind N, di Palma F, Birren BW, Nusbaum C, LindbladToh K, Friedman N, Regev A.Full-length transcriptome assembly from RNA-Seq data without a reference genome. Nat Biotechnol. 2011 May 15;29(7):644-52. doi: 10.1038/nbt.1883. PubMed PMID: 21572440; PubMed Central PMCID: PMC3571712.

25. Haas BJ, Papanicolaou A, Yassour M, Grabherr M, Blood PD, Bowden J, Couger MB, Eccles D, Li B, Lieber M, MacManes MD, Ott M, Orvis J, Pochet N, Strozzi F, Weeks N, Westerman R, William T, Dewey CN, Henschel R, LeDuc RD, Friedman N, Regev A. De novo transcript sequence reconstruction from RNA-seq using the Trinity platform for reference generation and analysis. Nat Protoc. 2013 Aug;8(8):1494-512. doi: 10.1038/nprot.2013.084. PubMed PMID: 23845962; PubMed Central PMCID: PMC3875132.

26. Holding ML, Margres MJ, Mason AJ, Parkinson CL, Rokyta DR. Evaluating the performance of De novo assembly methods for venom-gland transcriptomics. Toxins (Basel). 2018 Jun 19;10(6):249. doi: 10.3390/toxins10060249. PubMed PMID: 29921759; PubMed Central PMCID: PMC6024825.

27. Sze S-H. Computational Approaches for Studying Alternative Splicing in Nonmodel Organisms from RNA-SEQ Data. In: Mandoiu I, Zelikovsky A, editors. Computational Methods for Next Generation Sequencing Data Analysis. Hoboken, New Jersey: John Wiley \& Sons; 2016. p. 287-99.

28. Pertea G, Huang X, Liang F, Antonescu V, Sultana R, Karamycheva S, Lee Y, White J, Cheung F, Parvizi B, Tsai J, Quackenbush J. TIGR gene indices clustering tools (TGICL): a software system for fast clustering of large EST datasets. Bioinformatics. 2003 Mar 22;19(5):651-2. doi: 10.1093/ bioinformatics/btg034. PubMed PMID: 12651724.

29. Langmead B, Salzberg SL. Fast gapped-read alignment with Bowtie 2. Nat Methods. 2012 Mar 4;9(4):357-9. doi: 10.1038/nmeth.1923.

30. Li B, Dewey CN. RSEM: accurate transcript quantification from RNA-Seq data with or without a reference genome. BMC Bioinformatics. 2011 Aug 4;12:323. doi: 10.1186/1471-2105-12-323. PubMed PMID: 21816040; PubMed Central PMCID: PMC3163565.

31. Mortazavi A, Williams BA, McCue K, Schaeffer L, Wold B. Mapping and quantifying mammalian transcriptomes by RNA-Seq. Nat Methods. 2008 Jul;5(7):621-8. doi: 10.1038/nmeth.1226. PubMed PMID: 18516045.

32. Tan $\mathrm{CH}$, Tan KY, Fung SY, Tan NH. Venom-gland transcriptome and venom proteome of the malaysian king cobra (Ophiophagus hannah). BMC Genomics. 2015 Sep 10;16(1):687. doi: 10.1186/s12864-015-18282. PubMed PMID: 26358635; PubMed Central PMCID: PMC4566206. 
33. Tan KY, Tan $\mathrm{CH}$, Chanhome L, Tan NH. Comparative venom gland transcriptomics of Naja kaouthia (monocled cobra) from Malaysia and Thailand: elucidating geographical venom variation and insights into sequence novelty. Peer]. 2017 Apr 5;5: e3142. doi: 10.7717/peerj.3142. PubMed PMID: 28392982; PubMed Central PMCID: PMC5384570.

34. Chong HP, Tan KY, Tan NH, Tan CH. Exploring the diversity and novelty of toxin genes in Naja sumatrana, the equatorial spitting cobra from Malaysia through De Novo venom-gland transcriptomics. Toxins (Basel). 2019 Feb 11;11(2):104. doi: 10.3390/toxins11020104. PubMed PMID: 30754700; PubMed Central PMCID: PMC6409529.

35. Rokyta DR, Lemmon AR, Margres MJ, Aronow K. The venom-gland transcriptome of the eastern diamondback rattlesnake (Crotalus adamanteus). BMC Genomics. 2012 Jul 16;13:312. doi: 10.1186/1471-2164-13-312.

36. Tan CH, Tan KY. De Novo venom-gland transcriptomics of spine-bellied sea snake (Hydrophis curtus) from Penang, Malaysia-next-generation sequencing, functional annotation and toxinological correlation. Toxins. 2021 Feb 9;13(2):127. doi: 10.3390/toxins13020127. PubMed PMID: 33572266; PubMed Central PMCID: PMC7915529.

37. Waterhouse AM, Procter JB, Martin DMA, Clamp M, Barton GJ. Jalview Version 2--a multiple sequence alignment editor and analysis workbench. Bioinformatics. 2009 May 1;25(9):1189-91. doi: 10.1093/bioinformatics/ btp033. PubMed PMID: 19151095; PubMed Central PMCID: PMC2672624.

38. Edgar RC. MUSCLE: a multiple sequence alignment method with reduced time and space complexity. BMC Bioinformatics. 2004 Aug 19;5:113. doi: 10.1186/1471-2105-5-113. PubMed PMID: 15318951; PubMed Central PMCID: PMC517706.

39. Corrêa-Netto C, Junqueira-de-Azevedo ILM, Silva DA, Ho PL, Leitaode-Araujo M, Alves MLM, Sanz L, Foguel D, Zingali RB, Calvete JJ. Snake venomics and venom gland transcriptomic analysis of brazilian coral snakes, Micrurus altirostris and M. corallinus. J Proteomics. 2011 Aug 24;74(9):1795809. doi: 10.1016/j.jprot.2011.04.003. PubMed PMID: 21515432.

40. Margres MJ, Aronow K, Loyacano J, Rokyta DR. The venom-gland transcriptome of the eastern coral snake (Micrurus fulvius) reveals high venom complexity in the intragenomic evolution of venoms. BMC Genomics. 2013 Aug 2;14(1):531. doi: 10.1186/1471-2164-14-531. PubMed PMID: 23915248; PubMed Central PMCID: PMC3750283.

41. Wong $\mathrm{KY}$, Tan $\mathrm{CH}$, Tan $\mathrm{KY}$, Quraishi $\mathrm{NH}$, Tan $\mathrm{NH}$. Elucidating the biogeographical variation of the venom of Naja naja (spectacled cobra) from Pakistan through a venom-decomplexing proteomic study. J Proteomics. 2018 Mar 20;175:156-73. doi: 10.1016/j.jprot.2017.12.012. PubMed PMID: 29278784.

42. Dutta S, Chanda A, Kalita B, Islam T, Patra A, Mukherjee AK. Proteomic analysis to unravel the complex venom proteome of eastern India Naja naja: correlation of venom composition with its biochemical and pharmacological properties. J Proteomics. 2017 Mar 6;156:29-39. doi: 10.1016/j.jprot. 2016.12.018. PubMed PMID: 28062377.

43. Oh AMF, Tan CH, Ariaranee GC, Quraishi N, Tan NH. Venomics of Bungarus caeruleus (Indian krait): comparable venom profiles, variable immunoreactivities among specimens from Sri Lanka, India and Pakistan. J Proteomics. 2017 Jul 5;164:1-18. doi: 10.1016/j.jprot.2017.04.018. PubMed PMID: 28476572.

44. Oh AMF, Tan CH, Tan KY, Quraishi NH, Tan NH. Venom proteome of Bungarus sindanus (Sind krait) from Pakistan and in vivo cross-neutralization of toxicity using an indian polyvalent antivenom. J Proteomics. 2019 Feb 20;193:243-54. doi: 10.1016/j.jprot.2018.10.016. PubMed PMID: 30385415.

45. Tan CH, Tan KY, Ng TS, Sim SM, Tan NH. Venom proteome of spine-bellied sea snake (Hydrophis curtus) from Penang, Malaysia: toxicity correlation, immunoprofiling and cross-neutralization by sea snake antivenom. Toxins (Basel). 2018 Dec 23;11(1):3. doi: 10.3390/toxins11010003. PubMed PMID: 30583590; PubMed Central PMCID: PMC6356285.

46. Lauridsen LP, Laustsen AH, Lomonte B, Gutiérrez JM. Toxicovenomics and antivenom profiling of the eastern green mamba snake (Dendroaspis angusticeps). J Proteomics. 2016 Mar 16;136:248-61. doi: 10.1016/j.jprot. 2016.02.003. PubMed PMID: 26877184.

47. Laustsen AH, Lomonte B, Lohse B, Fernández J, Gutiérrez JM. Unveiling the nature of black mamba (Dendroaspis polylepis) venom through venomics and antivenom immunoprofiling: identification of key toxin targets for antivenom development. J Proteomics. 2015 Apr 24;119:126-42. doi: 10.1016/j.jprot.2015.02.002. PubMed PMID: 25688917.
48. Sanz L, Pla D, Pérez A, Rodríguez Y, Zavaleta A, Salas M, Lomonte B, Calvete JJ. Venomic analysis of the poorly studied desert coral snake, Micrurus tschudii tschudii, supports the 3 FTx/PLA $A_{2}$ dichotomy across Micrurus venoms. Toxins (Basel). 2016 Jun 7;8(6):178. doi: 10.3390/toxins8060178. PubMed PMID: 27338473; PubMed Central PMCID: PMC4926144.

49. Tan KY, Liew JL, Tan NH, Quah ESH, Ismail AK, Tan CH. Unlocking the secrets of banded coral snake (Calliophis intestinalis, Malaysia): a venom with proteome novelty, low toxicity and distinct antigenicity. J Proteomics. 2019 Feb 10;192:246-57. doi: 10.1016/j.jprot.2018.09.006. PubMed PMID: 30243938.

50. Tsetlin V. Snake venom alpha-neurotoxins and other 'three-finger' proteins. Eur J Biochem. 1999 Sep;264(2):281-6. doi: 10.1046/j.14321327.1999.00623.x. PubMed PMID: 10491072.

51. Kini RM, Doley R. Structure, function and evolution of three-finger toxins: mini proteins with multiple targets. Toxicon. 2010 Nov;56(6):855-67. doi: 10.1016/j.toxicon.2010.07.010 PubMed PMID: 20670641.

52. Fox JW, Serrano SMT. Exploring snake venom proteomes: multifaceted analyses for complex toxin mixtures. Proteomics. 2008 Feb;8(4):909-20. doi: 10.1002/pmic.200700777. PubMed PMID: 18203266.

53. Servent D, Ménez A. Snake neurotoxins that interact with nicotinic acetylcholine receptors. In: Massaro EJ, editor. Handbook of Neurotoxicology. Totowa, NJ: Humana Press; 2002. p.385-425.

54. Abbas N, Gaudioso-Tyzra C, Bonnet C, Gabriac M, Amsalem M, Lonigro A, Padilla F, Crest M, Martin-Eauclaire MF, Delmas P. The scorpion toxin Amm VIII induces pain hypersensitivity through gain-of-function of TTXsensitive $\mathrm{Na}^{+}$channels. Pain. 2013 Aug;154(8):1204-15. doi: 10.1016/j. pain.2013.03.037. PubMed PMID: 23685008.

55. Moran Y, Gordon D, Gurevitz M. Sea anemone toxins affecting voltagegated sodium channels--molecular and evolutionary features. Toxicon. 2009 Dec 15;54(8):1089-101. doi: 10.1016/j.toxicon.2009.02.028. PubMed PMID: 19268682; PubMed Central PMCID: PMC2807626.

56. Eitan M, Fowler E, Herrmann R, Duval A, Pelhate M, Zlotkin E. A scorpion venom neurotoxin paralytic to insects that affects sodium current inactivation: purification, primary structure, and mode of action. Biochemistry. 1990 Jun 26;29(25):5941-7. doi: 10.1021/bi00477a009. PubMed PMID: 2383565.

57. Schiavon E, Stevens M, Zaharenko AJ, Konno K, Tytgat J, Wanke E. Voltage-gated sodium channel isoform-specific effects of pompilidotoxins. FEBS J. 2010 Feb;277(4):918-30. doi: 10.1111/j.1742-4658.2009.07533.x. PubMed PMID: 20059541.

58. Fry BG, Vidal N, van der Weerd L, Kochva E, Renjifo C. Evolution and diversification of the Toxicofera reptile venom system. J Proteomics. 2009 Mar 6;72(2):127-36. doi: 10.1016/j.jprot.2009.01.009. PubMed PMID: 19457354.

59. Karbat I, Kahn R, Cohen L, Ilan N, Gilles N, Corzo G, Froy O, Gur M, Albrecht G, Heinemann SH, Gordon D, Gurevitz M. The unique pharmacology of the scorpion a-like toxin Lqh3 is associated with its flexible C-tail. FEBS J. 2007 Apr;274(8):1918-31. doi: 10.1111/j.17424658.2007.05737.x. PubMed PMID: 17355257.

60. Konno K, Hisada M, Naoki H, Itagaki Y, Yasuhara T, Nakata Y, Miwa A, Kawai N. Molecular determinants of binding of a wasp toxin (PMTXs) and its analogs in the $\mathrm{Na}^{+}$channels proteins. Neurosci Lett. 2000 May 5;285(1):29-32. doi: 10.1016/s0304-3940(00)01017-x. PubMed Central PMCID: PMC10788700.

61. Bulaj G, DeLaCruz R, Azimi-Zonooz A, West P, Watkins M, Yoshikami $D$, Oliveira BM. Delta-conotoxin structure/function through a cladistic analysis. Biochemistry. 2001 Nov 6;40(44):13201-8. doi: 10.1021/bi010 683a. PubMed PMID: 11683628.

62. Gunning SJ, Chong Y, Khalife AA, Hains PG, Broady KW, Nicholson GM. Isolation of delta-missulenatoxin-Mb1a, the major vertebrate-active spider delta-toxin from the venom of Missulena bradleyi (Actinopodidae). FEBS Lett. 2003 Nov 6;554(1-2):211-8. doi: 10.1016/S0014-5793(03)01175-x. PubMed PMID: 14596942.

63. Moran Y, Kahn R, Cohen L, Gur M, Karbat I, Gordon D, Gurevitz M. Molecular analysis of the sea anemone toxin Av3 reveals selectivity to insects and demonstrates the heterogeneity of receptor site- 3 on voltage-gated $\mathrm{Na}^{+}$channels. Biochem J. 2007 Aug 15;406(1):41-8. doi: 10.1042/BJ20070233. PubMed PMID: 17492942; PubMed Central PMCID: PMC1948988. 
64. Takasaki C, Yoshida H, Shimazu T, Teruuchi T, Toriba M, Tamiya N. Studies on the venom components of the long-glanded coral snake, Maticora bivirgata. Toxicon. 1991;29(2):191-200. doi: 10.1016/0041-0101(91)90103x. PubMed PMID: 2048137.

65. Chien KY, Chiang CM, Hseu YC, Vyas AA, Rule GS, Wu W. Two distinct types of cardiotoxin as revealed by the structure and activity relationship of their interaction with zwitterionic phospholipid dispersions. J Biol Chem. 1994 May 20;269(20):14473-83. PubMed PMID: 8182052.

66. Chiang CM, Chien KY, Lin HJ, Lin JF, Yeh HC, Ho PL, Wu WG. Conformational change and inactivation of membrane phospholipid-related activity of cardiotoxin $\mathrm{V}$ from Taiwan cobra venom at acidic $\mathrm{pH}$. Biochemistry. 1996 Jul 16;35(28):9167-76. doi: 10.1021/bi952823k. PubMed PMID: 8703922.

67. Tsai IH, Tsai HY, Saha A, Gomes A. Sequences, geographic variations and molecular phylogeny of venom phospholipases and threefinger toxins of eastern India Bungarus fasciatus and kinetic analyses of its Pro31 phospholipases A. FEBS J. 2007;274(2):512-25. doi: 10.1111/j.17424658.2006.05598.x. PubMed PMID: 17166178.

68. Qian YC, Fan CY, Gong Y, Yang SL. cDNA cloning and sequence analysis of six neurotoxin-like proteins from Chinese continental banded krait. Biochem Mol Biol Int. 1998;46(4):821-8. doi: 10.1080/15216549800204362. PubMed PMID: 9844743.

69. Fujimi TJ, Nakajyo T, Nishimura E, Ogura E, Tsuchiya T, Tamiya T. Molecular evolution and diversification of snake toxin genes, revealed by analysis of intron sequences. Gene. 2003;313:111-8. doi: 10.1016/s0378-1119 (03)00637-1. PubMed PMID: 12957382.

70. Tan $\mathrm{CH}$, Wong $\mathrm{KY}$, Tan NH, Ng TS, Tan KY. Distinctive distribution of secretory phospholipases $A_{2}$ in the venoms of afro-asian cobras (subgenus: Naja, Afronaja, Boulengerina and Uraeus). Toxins (Basel). 2019 Feb 14;11(2):116. doi: 10.3390/toxins11020116. PubMed PMID: 30769779; PubMed Central PMCID: PMC6410299.

71. Tan KY, Wong KY, Tan NH, Tan CH. Quantitative proteomics of Naja annulifera (sub-saharan snouted cobra) venom and neutralization activities of two antivenoms in Africa. Int J Biol Macromol. 2020 Apr 24;158:605-16. doi: 10.1016/j.ijbiomac.2020.04.173. PubMed Central PMCID: PMC32339578.

72. Doley R, Zhou X, Kini RM. Snake venom phospholipase A2 enzymes. In: Mackessy SP, editor. Handbook of venoms and toxins of reptiles. 1st ed.London, UK: CRC Press Inc; 2009. p. 173-215.

73. Pereira MF, Novello JC, Cintra ACO, Giglio JR, Landucci ET, Oliveira $B$, Marangoni S. The amino acid sequence of bothropstoxin-II, an Asp49 myotoxin from Bothrops jararacussu (Jararacucu) venom with low phospholipase A2 activity. J Protein Chem. 1998 May;17(4):381-6. doi: 10.1023/a:1022563401413. PubMed PMID: 9619591.

74. Zhang HL, Xu SJ, Wang QY, Song SY, Shu YY, Lin ZJ. Structure of a cardiotoxic phospholipase A2 from Ophiophagus hannah with the "pancreatic loop". J Struct Biol. 2002 Jun;138(3):207-15. doi: 10.1016/s1047-8477(02)00022-9.

75. Fohlman J, Eaker D, Karlsoon E, Thesleff S. Taipoxin, an extremely potent presynaptic neurotoxin from the venom of the australian snake taipan (Oxyuranus s. scutellatus). Isolation, characterization, quaternary structure and pharmacological properties. Eur J Biochem. 1976 Sep 15;68(2):457-69. doi: 10.1111/j.1432-1033.1976.tb10833.x. PubMed PMID: 976268.
76. Pearson JA, Tyler MI, Retson KV, Howden MEH. Studies on the subunit structure of textilotoxin, a potent presynaptic neurotoxin from the venom of the Australian common brown snake (Pseudonaja textilis). 3. The complete amino-acid sequences of all the subunits. Biochim Biophys Acta. 1993 Feb 13;1161(2-3):223-9. doi: 10.1016/0167-4838(93)90217-f. PubMed Central PMCID: PMC8431471.

77. Francis BR, da Silva Júnior NJ, Seebart C, Casais e Silva LL, Schmidt JJ, Kaiser II. Toxins isolated from the venom of the brazilian coral snake (Micrurus frontalis frontalis) include hemorrhagic type phospholipases A2 and postsynaptic neurotoxins. Toxicon. 1997 Aug;35(8):1193-203. doi: 10.1016/s0041-0101(97)00031-7. PubMed PMID: 9278969.

78. Huang MZ, Gopalakrishnakone P. Pathological changes induced by an acidic phospholipase A2 from Ophiophagus hannah venom on heart and skeletal muscle of mice after systemic injection. Toxicon. 1996 Feb;34(2):201-11. doi: 10.1016/0041-0101(95)00128-x. PubMed PMID: 8711754.

79. Wong KY, Tan CH, Tan NH. Venom and purified toxins of the spectacled cobra (Naja naja) from Pakistan: insights into toxicity and antivenom neutralization. Am J Trop Med Hyg. 2016 Jun 1;94(6):1392-9. doi: 10.4269/ ajtmh.15-0871. PubMed PMID: 27022154; PubMed Central PMCID: PMC4889763.

80. Tan $\mathrm{CH}$, Wong KY, Tan KY, Tan NH. Venom proteome of the yellowlipped sea krait, Laticauda colubrina from Bali: insights into subvenomic diversity, venom antigenicity and cross-neutralization by antivenom. J Proteomics. 2017 Aug 23;166:48-58. doi: 10.1016/j.jprot.2017.07.002. PubMed PMID: 28688916.

81. Fox JW, Serrano SMT. Structural considerations of the snake venom metalloproteinases, key members of the $M 12$ reprolysin family of metalloproteinases. Toxicon. 2005 Jun 15;45(8):969-85. doi: 10.1016/j. toxicon.2005.02.012. PubMed PMID: 15922769.

82. Gutierrez JM, Ruvacodo A, Escalante T. Snake venom metalloproteinases Biological roles and participation in the pathophysiology of envenomation. In: Mackessy SP, editor. Handbook of venoms and toxins of reptiles. 1st ed. London, UK: CRC Press Inc.; 2009. p. 115-38.

83. Markland Jr FS, Swenson S. Snake venom metalloproteinases. Toxicon. 2013 Feb;62:3-18. doi: 10.1016/j.toxicon.2012.09.004. PubMed PMID: 23000249.

84. Fox JW, Serrano SMT. Insights into and speculations about snake venom metalloproteinase (SVMP) synthesis, folding and disulfide bond formation and their contribution to venom complexity. FEBS J. 2008 Jun;275(12):301630. doi: 10.1111/j.1742-4658.2008.06466.x. PubMed PMID: 18479462.

85. Rodrigues RS, Boldrini-França J, Fonseca FPP, de la Torre P, HenriqueSilva F, Sanz L, Calvete JJ, Rodrigues VM. Combined snake venomics and venom gland transcriptomic analysis of Bothropoides pauloensis. J Proteomics. 2012 May 17;75(9):2707-20. doi: 10.1016/j.jprot.2012.03.028. PubMed PMID: 22480909

86. Vogel C, Marcotte EM. Insights into the regulation of protein abundance from proteomic and transcriptomic analyses. Nat Rev Genet. 2012 Mar 13;13(4):227-32. doi: 10.1038/nrg3185. PubMed PMID: 22411467; PubMed Central PMCID: PMC3654667. 